\title{
Solving a multi-objective location routing problem for infectious waste disposal using hybrid goal programming and hybrid genetic algorithm
}

\author{
Narong Wichapa* and Porntep Khokhajaikiat
}

Department of Industrial Engineering, Faculty of Engineering, Khon Kaen University, Khon Kaen, 40002, Thailand

\begin{tabular}{l}
\hline C H R O N I C L E \\
\hline Article history: \\
Received January 152017 \\
Received in Revised Format \\
April 12017 \\
Accepted April 112017 \\
Available online \\
April 122017 \\
\hline Keywords: \\
Location routing problem \\
Multi-objective facility location \\
problem \\
Vehicle routing problem \\
Fuzzy analytic hierarchy process \\
Genetic algorithm \\
Goal programming
\end{tabular}

\section{A B S T R A C T}

\begin{abstract}
Infectious waste disposal remains one of the most serious problems in the medical, social and environmental domains of almost every country. Selection of new suitable locations and finding the optimal set of transport routes for a fleet of vehicles to transport infectious waste material, location routing problem for infectious waste disposal, is one of the major problems in hazardous waste management. Determining locations for infectious waste disposal is a difficult and complex process, because it requires combining both intangible and tangible factors. Additionally, it depends on several criteria and various regulations. This facility location problem for infectious waste disposal is complicated, and it cannot be addressed using any standalone technique. Based on a case study, 107 hospitals and 6 candidate municipalities in UpperNortheastern Thailand, we considered criteria such as infrastructure, geology and social \& environmental criteria, evaluating global priority weights using the fuzzy analytical hierarchy process (Fuzzy AHP). After that, a new multi-objective facility location problem model which hybridizes fuzzy AHP and goal programming (GP), namely the HGP model, was tested. Finally, the vehicle routing problem (VRP) for a case study was formulated, and it was tested using a hybrid genetic algorithm (HGA) which hybridizes the push forward insertion heuristic (PFIH), genetic algorithm (GA) and three local searches including 2-opt, insertion-move and interexchange-move. The results show that both the HGP and HGA can lead to select new suitable locations and to find the optimal set of transport routes for vehicles delivering infectious waste material. The novelty of the proposed methodologies, HGP, is the simultaneous combination of relevant factors that are difficult to interpret and cost factors in order to determine new suitable locations, and HGA can be applied to determine the transport routes which provide a minimum number of vehicles and minimum transportation cost under the actual situation efficiently in this case.
\end{abstract}

\section{Introduction}

The infectious waste disposal remains a serious problem in healthcare waste management of almost every country. During the past few years, there has been an increase in the level of public concern about the healthcare waste management on a worldwide basis (Hansakul et al., 2010). The collection, transportation and disposal of infectious waste, when improperly handled, may cause substantial harm to

* Corresponding author Tel.: +66-850028205

E-mail: wnarong@kkumail.com (N. Wichapa)

(c) 2018 Growing Science Ltd. All rights reserved. doi: $10.5267 /$ j.ijiec.2017.4.003 
adverse health and environmental effects (Hansakul et al., 2010; Miyazaki \& Une, 2005). Selecting suitable locations for the construction of facilities for infectious waste disposal is the first and the most important step for environmental pollution control. Location selection for infectious waste disposal is a difficult and complicated process because it must comply with the requirements of regulations of each country and concurrently must minimize social, environmental and economic impacts (Nazari et al., 2012). In Thailand, the system of infectious waste disposal has been problematic since healthcare was reformed in 1977 (Hansakul et al., 2010). Governmental and public concern has afterward risen over insufficient collection of infectious waste for disposal, even though public hospitals have then own incinerators to dispose of their infectious waste material, because of social and environmental concern, many incinerators inside public hospitals have been shutdown lately. These public hospitals eventually need to use services from outside waste disposal agencies. However, the outside waste disposal agencies are not able to dispose of existing infectious waste material effectively. For example, they have no standard guidelines for work and transport. Transporting infectious waste from hospitals run by the private transport sector did not meet the regulatory requirements for safety, including illegal dumping and illegal disposal in inappropriate places. In addition, infectious waste collection by the private sector was slow and did not meet the requirements of each hospital. As a result, the government of Thailand set up a policy to encourage the establishment of new disposal centers at potential municipalities, in order to address the above problems and to increase the efficiency of infectious waste disposal. These new disposal centers must be able to serve nearby hospitals, and concurrently must reduce environmental, social, and economic factors and achieve maximum benefit. New disposal centers need to have planned transport routes in order to provide the lowest transportation costs and to serve those community hospitals in accordance with their routine. Therefore, building new disposal centers and finding the transport routes for infectious waste more effectively is becoming an issue that is particularly important.

Community hospitals, with 107 in the Upper Northeast of Thailand under the Ministry of Public Health, are one of the medical institutions that have often found common problems because they are far from the existing sites of outside waste disposal agencies. As a result, this can cause the above mentioned problems. To address such problems, the government of Thailand has designated local governments (Municipalities) directly responsible for new building of infectious waste disposal sites. The new disposal centers for this case pose complex problems, because there are many relevant factors which need to be considered, such as environmental, social and geological factors. In this problem, maximization of satisfaction level of relevant factors is as important as minimization of costs. The higher the satisfaction level, the lower the probability for disposal centers to cause damage to the biophysical environment and the ecology of the neighboring area. Certainly, both perspectives of relevant factors and costs must be considered in finding an optimal transportation network, and to achieve maximum benefit we need to assign the appropriate transport routes for each new disposal center in order to provide minimum transportation cost.

From the literature reviewed and due to the complexity of this issue, the study process for this case is divided into two phases. The first phase is to select suitable locations for infectious waste disposal centers. This is a multi-criteria decision making (MCDM) problem. There are many relevant factors involved, both quantitative and qualitative factors, including the need to allocate resources simultaneously. For this reason, it is necessary to choose appropriate tools for solving this problem. Since the fuzzy analytic hierarchy process (fuzzy AHP) is a contemporary tool, it is suitable to address the MCDM problems which are difficult to interpret and the goal programming model (GP model) is a popular tool to solve multi-objective problems that need to allocate resources. Hence, this phase needs to use integrating fuzzy AHP technique with the GP model, namely the HGP model, in order to solve this complex problem to minimize the total cost and to maximize the total location weight under the existing constraints. The second phase is to assign the appropriate transporting routes for each selected disposal center in order to provide minimum transportation cost/minimum total distance. The Vehicle Routing Problem (VRP) belongs to the class of NP-hard problems which are difficult to solve by exact solution techniques because the exact solution techniques become highly time-consuming as the problem 
instances increase in size. Therefore, heuristic techniques will be applied to solve VRP in this case. Due to the combinatorial nature of the VRP and the Genetic Algorithm's efficiency in solving combinatorial problems, the Genetic Algorithm (GA), the most famous meta-heuristic algorithm in the world (Golmohammadi et al., 2016), is one of the meta-heuristics which is often used to solve the VRPs in the literature (Ahmadizar et al., 2015; Karakatič \& Podgorelec, 2015; Razali, 2015), and the success of this is mainly due to its simplicity, easy operation, and great flexibility (Ho et al., 2008). However, this traditional algorithm has been developed in many ways by integrating the GA with other tools to handle the various problems efficiently. Hence, a new hybrid genetic algorithm (HGA) is developed to deal with the VRP in this paper. The major difference between the traditional GA and HGA in this case is that the initial solutions of traditional GA are generated randomly, but the initial solutions of HGA are generated using the Push Forward Insertion Heuristic (PFIH), and three local searches, 2-Opt-move, Insertion-move and $\lambda$-interchange-move, are added to increase the efficiency of the algorithm. These are the major reasons why HGA is selected as a suitable tool in this paper. The two proposed methodologies, HGP and HGA, try to minimize the total cost of the transportation network and maximize the satisfaction level of its stake holders, under relevant constraints that exist in the decision environment.

The rest of the paper is organized as follows. Section 2, section 3 and section 4 are Related Literature, Methodology and Application respectively, and finally, section 5 is the Conclusion.

\section{Related Literature}

The location routing problem (LRP) is clearly related to both the facility location problem (FLP) and the vehicle routing problem (VRP). LRP is an NP-hard problem, as it encompasses two NP-hard problems (Nagy \& Salhi, 2007). LRP for the infectious waste management problem in this case is complicated, and it is a large and complex problem which cannot be solved using existing optimization techniques only. Hence, based on a paper of Alumur and Kara (2007), solving the LRP for the hazardous waste management problem could have two phases. The first phase would choose the suitable locations for the facilities, and the second phase would decide the optimal transport routes.

The theory of FLP has been studied for many decades, but it is accepted by all researchers that Weber's book of 1909 is the essential origin of this theory (Farahani et al., 2010). Traditional FLP is a single objective problem. The location network (depots, customers and arcs) that incurs the minimum total distance/lowest total cost is regarded as an optimal solution. Many researchers (Dantrakul et al., 2014; Etemadnia et al., 2015; Guastaroba \& Speranza, 2014; Rahmani \& MirHassani, 2014) have proposed solving techniques such as mathematical techniques (heuristic and optimization techniques) only. However, with some complex problems such as selecting sites for hazardous material waste disposal, choosing sites for nuclear power plants, location selection for infectious waste disposal, these problems are very important decisions because they are costly and hard to reverse. These are multi-criteria decision making (MCDM) problems, for which there are many relevant factors such as costs, social responsibility and environmental awareness. Therefore, one of the most essential difficulties to solving these problems is to choose the suitable techniques for evaluating these complicated criteria. The multi-criteria/objective facility location problem (MCFLP/MOFLP) for infectious waste disposal in this case is one the MCDM problem. A group of researchers (Dantrakul et al., 2014; Guo, Cheng, \& Wang, 2017; Kalcsics, Nickel, Pozo, Puerto, \& Rodríguez-Chía, 2014; Steiner, Datta, Steiner Neto, Scarpin, \& Rui Figueira, 2015) proposed mathematical techniques to solve MCDM problems which need to deal with environmental restrictions, whereas another group (Choudhary \& Shankar, 2012; Hanine et al., 2016; Kahraman et al., 2003) often proposed MCDM tools to solve complex problems which are difficult to interpret. The disadvantages of MCDM tools alone cause them to be unable to handle existing environmental restrictions in some special problems, and the disadvantages of mathematical techniques make them unable to address complex problems which are difficult to interpret. Hence, some researchers (Badri, 1999; Ho et al., 2008; Ho, 2007) have taken traditional MCDM tools combined with mathematical techniques in order to deal with environmental restrictions simultaneously. One traditional MCDM tool 
often suggested for solving complex problems is the analytic hierarchy process (AHP), because it is a simple and powerful approach (Russo \& Camanho, 2015; Singh \& Nachtnebel, 2016). However, AHP has the weakness that it cannot reflect the human thinking style. Later, the fuzzy analytic hierarchy process (Fuzzy AHP) based on the fuzzy set theory of Zadeh (1965) was developed in order to overcome this weak point, and this contemporary tool is used to solve MCDM problems which are difficult to interpret instead of the traditional AHP. Mathematical models, linear programming model (LP model) and goal programming model (GP model), are often combined with the MCDM tools in order to address some special problems or complex problems in the literature. The LP model is formulated to solve single objective problems, whereas the GP model is formulated to solve multi-objective problems. The GP model has been studied by Charnes et al. (1955) for solving the unsolvable LP model. Hence, recently, some researchers have taken Fuzzy AHP with mathematical models to solve MCDM problems instead of traditional combined models. Although fuzzy AHP only is widely used to solve MCDM problems in many fields, there are few papers that report the combined fuzzy AHP with mathematical techniques to solve MCDM under existing environmental restrictions. For example, He et al. (2012) proposed an integrated fuzzy AHP-Linear Programming model for solving the multi-criteria transshipment problem to maximize service level and minimize logistics costs simultaneously. Kannan et al. (2013) presented a combined fuzzy MCDM method and GP model for supplier selection in a green supply chain. Also, recently, Ozgen and Gulsun (Ozgen \& Gulsun, 2014) proposed a combined LP model and fuzzy AHP for solving the capacitated MOFLP. Although the fuzzy AHP is widely used in many fields at present, the application of this technique to solve the MCFLP problems is complex, depending on the nature of each problem. For this reason, choosing the appropriate combined model will enhance the confidence of decision makers for selecting the suitable locations for infectious waste disposal by considering both relevant costs and environmental impacts under available resources limitations.

The basic VRP consists of a set of customers, each customer with known demands, which must be serviced from a single depot. Transport routes for each vehicle are required, starting and finishing at same depot, so that each demand will be satisfied and each customer is assigned to exactly one vehicle. Each vehicle can carry a limited weight and may also be limited in the total distance it can travel (Baker \& Ayechew, 2003). The objective of the VRP is to minimize the total distance/transportation cost. The first VRP model was proposed by Dantzig and Ramser (1959) and Clarke and Wright (1964) first incorporated more than one vehicle in the problem formulation. Consequently, these two studies may be considered as being first in the VRP literature as we know it. Many real life VRPs are usually large, so that optimization techniques cannot be used to solve them. As the VRPs are an NP-hard problem (Lenstra \& Kan, 1981), the size of problems that can be solved optimally is limited. Due to the size of problems and frequency of real world problems, the commercial solvers tend to apply various heuristic techniques. Given the difficulty of VRPs, many heuristic algorithms do not seek global optimal solutions, but rather seek to provide fast near-optimal solutions. For the past two decades, meta-heuristics have been developed to solve VRPs instead of traditional heuristics in order to find good solutions quickly. Later, many researchers have frequently used meta-heuristics (Birim, 2016; Brandão, 2009, 2011; Kalayci \& Kaya, 2016; Lai et al., 2016; Tang et al., 2013; Tavakkoli-Moghaddam et al., 2007) such as Tabu search (TS), Ant colony optimization (ACO), Simulated annealing (SA) and Genetic algorithm (GA) to solve various VRPs in some real world problems. Nowadays there are many new meta-heuristics that occur in the literature such as differential evolution (DE) and Bee colony (BC). However, there are no tools to confirm which is best, depending on each situation and individual preference. GA is one of the traditional meta-heuristics which is often used to solve VRPs, but nowadays this tool is often used to deal with various VRPs by integrating with other tools in order to improve the solution efficiency. The new various algorithms of this tool have been continuously developed depending on the preferences and expertise of each researcher. Since its accomplishment is mainly due to its simplicity, easy operation, and great flexibility, integrating traditional GA with other tools is suitable and sufficient for solving the VRP in this case study. These are the major reasons why HGA was selected as a suitable tool in this paper. 
According to the above literature review, the MOFLP model in this case is needed to formulate to address the location selection problem for infectious waste disposal. The GP model is suitable to solve multiobjective problems in the literature, and fuzzy AHP has often been applied to solve MCDM problems which are difficult to interpret. Since stand-alone fuzzy AHP cannot deal with the environmental restrictions of this problem, choosing hybridized fuzzy AHP and GP techniques are reasonable to solve MOFLP in this case. Consequently, the first phase presents a new MOFLP model for selecting infectious waste disposal centers, namely the HGP model, which differs from the literature by taking advantage of the strong points of each method, while overcoming their weak points. After that, in the second phase, HGA is used to solve the VRP in this case because GA is one of various algorithms which are suitable for solving VRPs. The new HGA algorithm is developed to solve VRP in a case study, in order to find the minimum number of vehicles and minimum total distance.

\section{Methodology}

This paper offers two methodologies for the location routing problem for infectious waste disposal. The first methodology, the HGP model, is used to select the suitable disposal centers in order to achieve the lowest total cost and maximum total location weight. The second methodology, HGA, is used to solve VRP for selecting suitable routes which provide minimum total distance. Details of the conceptual framework are shown in Fig. 1.

The first step of the study process is to define relevant factors for selecting the candidate locations/candidate municipalities. The selection of candidate municipalities is found from legislation and expertise, similarly to every nation. For example, in Thailand, all locations of municipalities will be first considered based on the Thai legislation and the encouragement of government policy. Next, these municipalities that comply with Thai legislation and government policy will also be considered based on the regulations of each local government. Finally, experts define relevant criteria that impact location selection for infectious waste disposal, and then they decide to choose these locations as candidate municipalities. The second step is to compute the location weights for all candidate municipalities using fuzzy AHP. A high location weight means that it is better than a low location weight. The third step is to build and compute a HGP model to select the new suitable locations for infectious waste disposal. The final step is to build and compute HGA for VRP to select the optimal routes for each new suitable location.

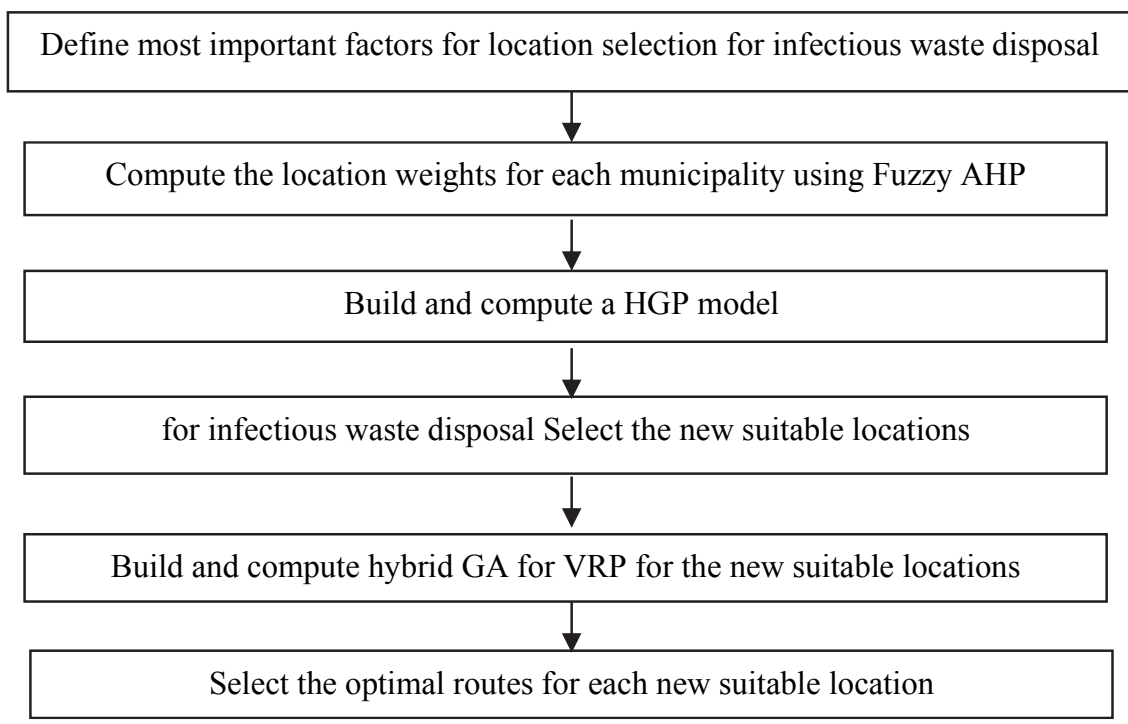

Fig. 1. The main steps of the study process 


\subsection{Fuzzy AHP}

Since the traditional AHP is insufficient for dealing with the imprecise or vague nature of linguistic assessment, contemporary AHP, namely fuzzy AHP, is used to evaluate the priority weights instead of the traditional AHP. In this paper, triangular fuzzy numbers are employed in the pair-wise comparison as shown in Table 1.

Table 1

The nine scale of fuzzy AHP

\begin{tabular}{cl}
\hline TFN & Definition \\
\hline$(1,1,1)$ & Equal \\
$(2,3,4)$ & Moderate \\
$(4,5,6)$ & Strong \\
$(6,7,8)$ & Very strong \\
$(8,9,9)$ & Extreme \\
$\widetilde{2}, \widetilde{4}, \widetilde{6}, \widetilde{8}$ & Intermediate values between the two adjacent judgments \\
\hline
\end{tabular}

The step of evaluation for priority weights of each candidate location is calculated by fuzzy arithmetic operations, which can be shown by equations (1-5). Let $\widetilde{A}_{k}=\left\{\widetilde{a}_{i j k}\right\}$ be the fuzzy pair-wise comparison matrices for each decision maker $k$, and $K$ is the number of decision makers. $\widetilde{A}_{k}$ can be shown in Eq. (1).

$$
\widetilde{A}_{k}=\left[\begin{array}{cccc}
\widetilde{a}_{11 k} & \tilde{a}_{12 k} & \cdots & \widetilde{a}_{1 n k} \\
\widetilde{a}_{21 k} & \widetilde{a}_{22 k} & \cdots & \widetilde{a}_{2 n k} \\
\vdots & \vdots & \vdots & \vdots \\
\widetilde{a}_{n 1 k} & \widetilde{a}_{n 2 k} & \cdots & \widetilde{a}_{n n k}
\end{array}\right], k=1,2, \ldots, K
$$

where $\tilde{a}_{i j k}=\left(l_{i j k}, m_{i j k}, u_{i j k}\right)$ is the triangular fuzzy numbers of the $k^{\text {th }}$ decision maker, $l_{i j k}, m_{i j k}$ and $u_{i j k}$ are least possible value, mode value and highest possible value respectively. The fuzzy arithmetic operations on the triangular fuzzy numbers can be expressed as follows:

Addition: $\quad M_{1} \oplus M_{2}=\left(l_{1}+l_{2}, m_{1}+m_{2}, u_{1}+u_{2}\right)$

Multiplication: $M_{1} \otimes M_{2}=\left(l_{1} \cdot l_{2}, m_{1} \cdot m_{2} \cdot m_{2}, u_{1} \cdot u_{2}\right)$

Division: $\quad M_{1} / M_{2}=\left(l_{1} / u_{2}, m_{1} / m_{2}, u_{1} / l_{2}\right)$

Reciprocal: $\quad M_{1}^{-1}=\left(1 / u_{1}, 1 / m_{1}, 1 / l_{1}\right)$

where $M_{1}$ and $M_{2}$ are two triangular fuzzy numbers, $M_{1}=\left(l_{1}, m_{1}, u_{1}\right)$ and $M_{2}=\left(l_{2}, m_{2}, u_{2}\right)$. Afterwards, the steps of the fuzzy AHP include the following steps:

\section{- Build the hierarchical structure}

The relevant decision factors can be defined by asking questions to experts questions about which criterion is more important with regard to the goal. After that, these relevant decision factors are decomposed into a multi-level hierarchical structure, as shown in Figure 2. At level " 0 ", the goal is to choose new suitable locations. At level " 1 ", the criteria are $\mathrm{C}_{1}, \mathrm{C}_{2}, \ldots, \mathrm{C}_{\mathrm{n}}$, and at level " 2 ", the alternatives are location $1\left(\mathrm{~L}_{1}\right)$, location $2\left(\mathrm{~L}_{2}\right)$ and location $\mathrm{n}\left(\mathrm{L}_{\mathrm{n}}\right)$. 


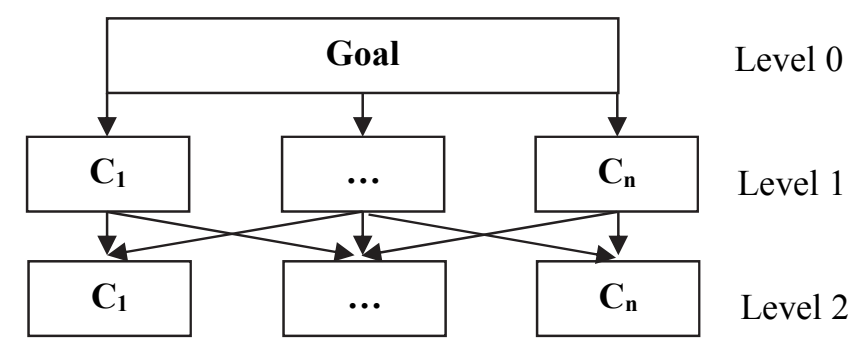

Fig. 2. A multi-level hierarchical structure for location selection

\section{- Construct the comparison matrices}

The comparison matrices of each decision maker $k$ can be constructed using Eq. (1). After that, integrating the comparison matrices from all experts using the fuzzy geometric mean method (Dong \& Cooper, 2016) is as shown in Eq. (6)

$$
\widetilde{G}=\left(\prod_{i=1}^{K} \widetilde{a}_{i j k}\right)^{1 / K}
$$

where $\widetilde{G}$ is the aggregated pair-wise comparison matrix.

- Estimate priority weights of each level

After aggregation of comparison matrices from all experts, the three steps provide a good approximation of the priority weights as follows.

Step 1: Sum the values in each column of the matrix by using Eq. (2).

Step 2: Divide all elements of the matrix with the sum of its column to generate the normalized matrix by using Eq. (4).

Step 3: Divide the sum of the normalized column of matrix by the number of criteria used $(n)$ to generate fuzzy priority weight vector.

Step 4: Convert the fuzzy priority weight vector to crisp priority weight vector by Eq. (7)

$$
d f \widetilde{a}_{i j}=\left\lfloor\left(u_{i j}-l_{i j}\right)+\left(m_{i j}-l_{i j}\right)\right\rfloor / 3+l_{i j} \quad \forall i, \forall j
$$

\section{- Compute the consistency ratio (CR)}

Step 1: Multiply the aggregated pair-wise comparison matrix by the crisp priority weight vector.

Step 2: Divide the weighted sum vector with criterion weight in step 1; average weighted sums $\left(\bar{w}_{i}\right)$ will be obtained for each row $i$ for the calculation in this step.

Step 3: Compute $\lambda_{\max }$ by Eq. (8).

$$
\lambda_{\max }=\sum_{i=1}^{n} \bar{w}_{i} / n
$$

Step 4: Compute the consistency index $(C I)$ by Eq. (9).

$$
C I=\left(\lambda_{\max }-n\right) /(n-1)
$$

Step 5: Compute the consistency ratio $(C R)$.

$$
C R=C I / R I
$$


$R I$ is defined using Table 2.

Table 2

List of random index values

\begin{tabular}{cccccccccc}
$\boldsymbol{n}$ & 1 & 2 & 3 & 4 & 5 & 6 & 7 & 8 & 9 \\
$\boldsymbol{R I}$ & 0 & 0 & 0.58 & 0.90 & 1.12 & 1.24 & 1.32 & 1.41 & 1.45 \\
\hline
\end{tabular}

A $C R$ value of 0.10 or less is accepted as a good consistency measure. If the value exceeds 0.10 , it is indicative of inconsistent judgment, and it should be revised.

- Compute the final priority weights for each alternative

The priority weight of each alternative is multiplied by the sub-criteria weights and aggregated to get local priority weights with respect to each criterion. The local priority weights are then multiplied by the criteria weights and aggregated to get global priority weights/location weights. The best alternative/location is the maximum value of the global priority weights, and the value of a high location weight means that it is better than a low location weight.

\subsection{HGP model}

The multi-objective facility location problem model (MOFLP model) is formulated to determine the problem statement. The candidate municipalities are assumed to have enough space, budget and staffing, and the locations of the incinerators can be made anywhere within the candidate municipalities. Details of the mathematical model of this problem are shown below.

Indices

$i$ is the index of each municipality, $i=1,2, . ., m,(m=6)$.

$j$ is the index of each hospital, $j=1,2, . ., n,(n=107)$.

$k$ is the size of each incinerator, $k=1,2, . ., K,(K=3)$.

\section{Parameters}

$f_{k}$ is facility cost (baht/day).

$o k$ is operating cost (baht/day).

$c_{i j}$ is transportation cost between municipality $i$ and hospital $j$ (baht/day)

$d t_{i j}$ is actual distance between municipality $i$ and hospital $j(\mathrm{~km})$.

$u$ is unit transportation cost (baht $/ \mathrm{km})$.

$s_{k}$ is the size of each incinerator $i$.

$d_{j}$ is the demand of hospital $j(\mathrm{~kg} /$ day).

\section{Decision variables}

$X_{i j}$ is a binary decision variable; $X_{i j}=1$ if the hospital $j$ is served by municipality $i, X_{i j}=0$ otherwise. $Y_{i}$ is a non-negative integer decision variable; $Y_{i}=1$ if municipality $i$ is opened, $Y_{i}=0$ otherwise. $Z_{i k}$ is a binary decision variable; $Z_{i k}=1$ if the municipality $i$ is opened by selecting incinerator $k$, $Z_{i k}=0$ otherwise.

\section{Objective functions}

$$
\min Z_{1}=\sum_{i=1}^{m} \sum_{k=1}^{K} f_{k} \cdot Z_{i, k}+\sum_{i=1}^{m} \sum_{k=1}^{K} o_{k} \cdot Z_{i, k}+\sum_{i=1}^{m} \sum_{j=1}^{n} u \cdot d t_{i j} X_{i j}
$$




$$
\max Z_{2}=\sum_{i=1}^{m} w_{i} \cdot Y_{i}
$$

\section{Constraints}

$$
\begin{aligned}
& \sum_{i=1}^{m} X_{i j}=1 \quad \forall \quad j \quad(j=1,2, . ., n) \\
& \sum_{j=1}^{n} d_{j} \cdot X_{i j} \leq \sum_{k=1}^{K} s_{k} \cdot Z_{i k} \quad \forall i \quad(i=1 . . . m) \\
& \sum_{i=1}^{m} \sum_{k=1}^{K} s_{k} \cdot Z_{i, k} \geq \sum_{j=1}^{n} d_{j} \\
& \sum_{k=1}^{K} Z_{i k}=Y_{i} \quad \forall \quad i \quad(i=1 \ldots . m) \\
& X_{i j} \in\{0,1\} \\
& Y_{i} \in\{0,1\} \\
& Z_{i, k} \in\{0,1\}
\end{aligned}
$$

The objective function given by Eq. (11) will attempt to minimize the total cost (facility costs, operating costs and transportation cost). Eq. (12) will attempt to maximize total priority weight of candidate municipalities. Eq. (13) ensures that the demand of each hospital $j$ is fulfilled. Eq. (14) ensures that the service prepared by a site cannot exceed its capacity. Eq. (15) ensures that the sum of the services provided by a site cannot exceed the sum of its capacities and Equation (16) that the selected municipalities must use only $k$-size incinerators. Eqs. (17-19) are binary.

The two main objectives are shown in Eqs. (11-12), which can be converted to be hybrid goal programming (HGP) as follow: The objective can be written as Eq. (20), and the constraints of HGP model are shown in Eqs. (13-19) and Eq. (21) and Equation (22).

\section{Deviation variables}

$d_{i}{ }^{-}, d_{i}{ }^{+}$are vectors of under achievement and overachievement of targeted value for each objective.

\section{Additional parameters}

$w_{i}$ is final priority weights/location weights of municipality $i$.

$T C$ is target for total cost (defined by total cost of MSLP model).

$W_{o l}$ is objective's weight of total cost according to experts' opinions.

$W_{o 2}$ is objective's weight of fuzzy AHP according to experts' opinions.

\section{Objective functions of the HGP model}

$$
\min z=w_{o 1} d_{1}^{+}+w_{o 2} d_{2}^{-}
$$

\section{Constraints}

$$
\begin{aligned}
& \sum_{i=1}^{m} \sum_{k=1}^{K} f_{k} Z_{i, k} / T C+\sum_{i=1}^{m} \sum_{k=1}^{K} o_{k} Z_{i, k} / T C+\sum_{i=1}^{m} \sum_{j=1}^{K} c_{i j} X_{i j} / T C+d_{1}^{-}-d_{1}^{+}=1 \\
& \sum_{i=1}^{m} w_{i} Y_{i}+d_{2}^{-}-d_{2}^{+}=1
\end{aligned}
$$


The objective is to minimize the unwanted deviations, $d_{i}{ }^{-}, d_{i}{ }^{+}$; these deviations are deviation variables of under achievement and over achievement of targets for each objective. Since each objective target has different units, this has to normalize all units to 1.The optimal solution of the HGP model can be solved by LINGO 13.

\subsection{VRP model}

After obtaining the optimal solution from the fuzzy AHP model, these new locations are used to design the transport routes to achieve the lowest transportation cost. This section describes the notation and features that are common throughout the paper. Our formulation is based on the VRP model as shown in Fig. 3. Details of the transportation vehicle routing model are as follows:

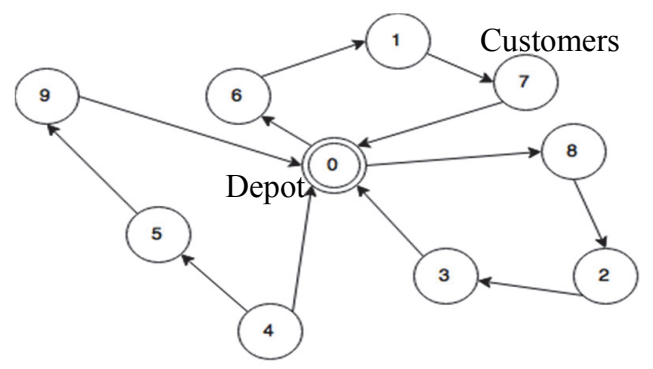

\section{Assumptions}

Fig. 3. Model of VRP

(1) The selected locations are known, and the hospital points are also known.

(2) The sum of infectious waste material should not be higher than the maximum load of transport vehicles.

(3) Each transport vehicle takes the selected location as the starting point, and then returns back to the selected location.

(4) The amount of infectious waste is determinate.

(5) One vehicle can serve multiple hospitals.

(6) Each vehicle travels from node $i$ to $j$ at a speed of 60 kilometers per hour.

\section{Indices}

The VRP model may be defined as the following graph theoretic problem. Let $G=(\mathrm{N}, \mathrm{A})$ be a complete graph where $N$ is the node set and $\mathrm{A}$ is the arc set. Nodes $j=2,3,4, \ldots, \mathrm{n}$ correspond to the hospitals or customers, whereas node 1 corresponds to the selected municipality or depot and $(i, j) \in A$. $K$ is a set of identical vehicles, which is available at the municipality.

\section{Parameters}

$d t_{i j}$ is actual distance between node $i$ and node $j(\mathrm{~km})$

$K$ is a set of identical vehicles. $K=1,2,3, \ldots, k$.

$N$ is vertex set. $N=1,2,3, \ldots, n$.

$q_{k}$ is capacity of $k^{\text {th }}$ vehicle. $(\mathrm{kg})$

$f_{k}$ is available vehicle cost (baht).

$d_{j}$ is the demand of hospital $j(\mathrm{~kg} /$ day).

$t_{i j}$ is traveling time between node $i$ and node $j$ (min.).

$T T$ is the maximum allowable time (min.).

\section{Decision variables}

$X_{i j k}$ is a binary decision variable; $X_{i j k}=1$ if vehicle $k$ moves from hospital $i$ to $j ; X_{i j k}=0$ otherwise.

$Z_{k}=1$ if vehicle $\mathrm{k}$ is used to service hospitals, $Z_{k}=0$ otherwise. 


$$
\min z=\sum_{i \in N} \sum_{j \in N} \sum_{k=1}^{K} d t_{i j} X_{i j k}
$$

\section{Constraints}

$$
\begin{array}{ll}
\sum_{i \in N} \sum_{j \in N, i \neq j} X_{i j k} \leq N Z_{k} & \forall k \in K \\
\sum_{j \in N, i \neq j} X_{1 j k} \leq 1 & \forall k \in K \\
\sum_{i \in N, i \neq j} X_{i 1 k} \leq 1 & \forall k \in K \\
\sum_{i \in N} X_{i p k}-\sum_{j \in N, i \neq j} X_{i p k}=0 & \forall p, p \in N, \forall k \in K \\
\sum_{k \in K} \sum_{i \in N, i \neq j} X_{i j k}=1 & \forall j \in N \\
\sum_{k \in K} \sum_{j \in N, i \neq j} X_{i j k}=1 & \forall i \in N \\
\sum_{i \in N} \sum_{j \in N, i \neq j} d_{j} X_{i j k} \leq q_{k} & \forall k \in K \\
\sum_{i \in N} \sum_{j \in N, i \neq j} t_{i j} X_{i j k} \leq T T & \forall k \in K \\
X_{i j k} \in\{0,1\} & \forall i \in N, \forall j \in N, \forall k \in K \\
Z_{k} \in\{0,1\} &
\end{array}
$$

Eq. (23) is to minimize the total distance. Eq. (24) is the number of arcs between node $i$ and node j, which is not more than the number of points, $N$. Eq. (25) and Eq. (26) ensure that the vehicle must go from the depot to the hospital only once. Equation (27) indicates the vehicle arrives at hospital point $j$ and also leaves from j. Eq. (28) and Eq. (29) indicate that all hospitals are visited only once. Equation (30) ensures that the total infectious waste collection transportation by vehicle $\mathrm{K}$ does not exceed the capacity of the vehicle itself. Eqs. (31) ensure that each vehicle k does not travel more than the maximum allowable time/maximum distance. Eq. (32) and Eq. (33) are binary decision variables. In this case study, since LINGO13 used a very long computational time to solve this problem, heuristic techniques are suitable for solving the VRP for the disposal centers. Details of this technique are shown in the next section.

\section{$3.4 H G A$}

The Genetic Algorithm (GA), proposed by Holland (Holland, 1992), is a meta-heuristic, similar to other meta-heuristics like simulated annealing (SA) and tabu search (TS). Traditional GA starts with an initial population of $\mathrm{n}$ random chromosomes (random solutions), and the GA maintains each random chromosome with associated fitness values. Parents are chosen to mate, on the basis of a value of probability distribution, producing offspring. For example, any chromosomes with higher fitness values are given more opportunities to reproduce, crossover and mutation. In the crossover phase, the GA attempts to swap a subsequence of two of the chosen chromosomes to create two offspring. 


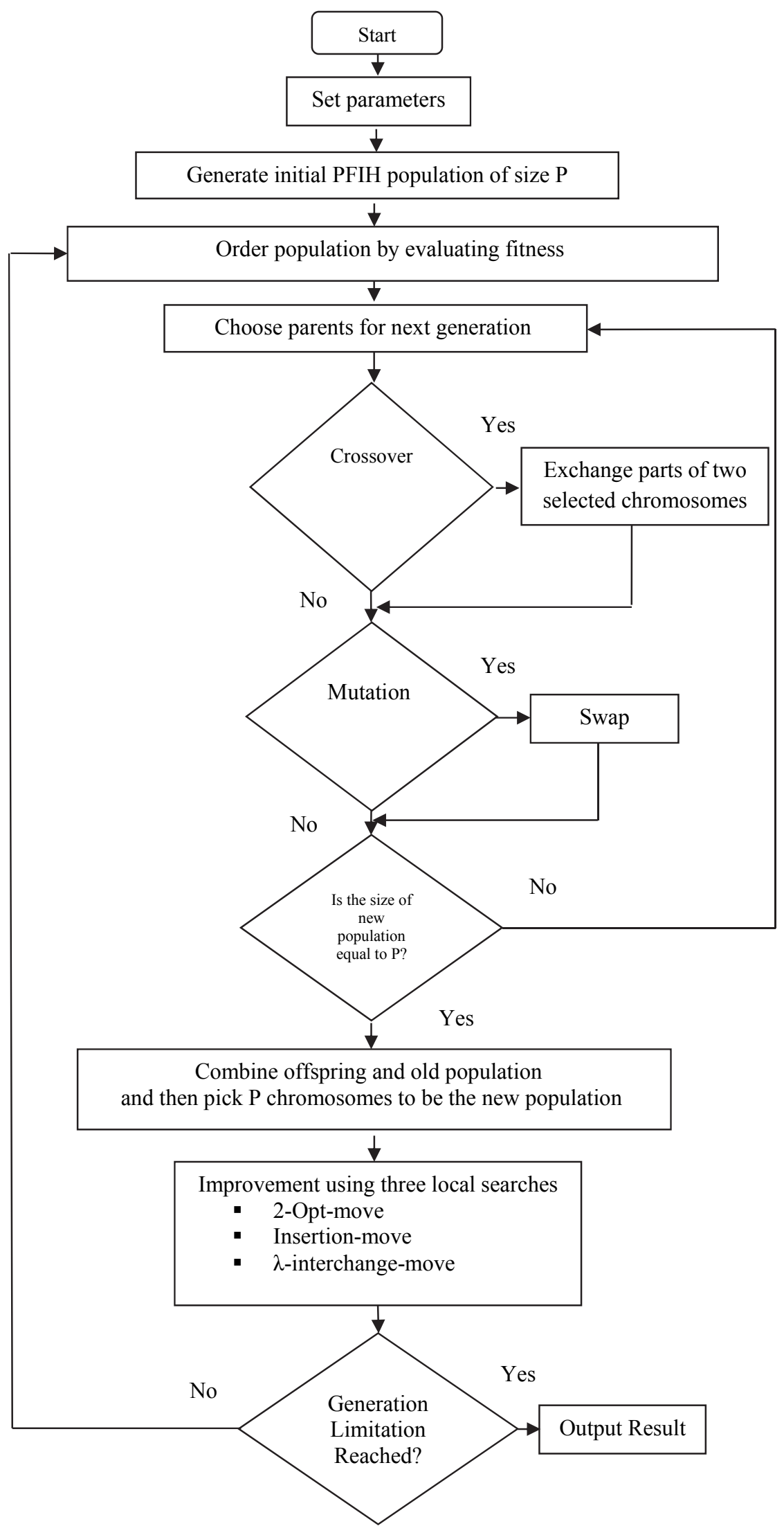

Fig. 4. Flow Chart of solution of VRP using HGA 
A new generation of chromosomes is formed by choosing some parents and some offspring in accordance with their fitness values, and by rejecting others to maintain the size constant of population. After the predetermined number of generations is created, the algorithm converges to the best chromosome, which hopefully represents the optimal solution of the problem. The performance of GA depends on important parameters such as the value of probability distribution of crossover, the value of probability distribution of mutation, the size of the population, the number of iterations, and this algorithm also depends on the fitness function. A hybrid genetic algorithm (HGA), which integrates Push-Forward Insertion Heuristic (PFIH) from Solomon's paper (Solomon, 1987), genetic algorithm (GA) and three local searches (Insertion-move, 2-Opt-move by Potvin and Rousseau (Potvin \& Rousseau, 1995) and $\lambda$-interchangemove by Osman and Christofides (Osman \& Christofides, 1994)), is proposed to deal with the VRP in this case. The main objectives of the HGA are to minimize number of vehicles (NV) and minimize the total distance (TD), under the limits of existing resources. Since traditional GA cannot find the good solutions adequately, the HGA will be formulated to solve this problem. The algorithm is demonstrated in Fig. 4. A flow chart of solution of VRP using HGA can be described as follows. Let P be the constant size of the population at each generation. An initial population will be generated using PFIH until the size of the population is equal to $\mathrm{P}$. The cost function for choosing the first customer/hospital $\left(C_{i}\right)$ is calculated using the following Eq. (34).

$$
C_{i}=-\alpha d d_{i}+\beta l_{i}+\gamma\left((p i / 360) d 0_{i}\right)
$$

$\alpha$ is the weight factor for the total distance travelled by a vehicle.

$\beta$ is the weight factor for the urgency of a customer.

$\gamma$ is the weight factor for the polar coordinate angle of a customer.

$d_{0 i}$ is the distance from depot to hospital $i$.

$l_{i}$ is the latest arrival time at hospital $i$.

$p_{i}$ is the polar coordinate angle of hospital $i$.

The unrouted customer/hospital with the lowest cost is selected as the first customer/hospital to be visited. The priority rule in Equation (34) for the selection of the hospital depends on the distance, latest time and polar coordinate angle. For details of PFIH see Solomon (Solomon, 1987), Brandão and Vasconcelos (Brandão de Oliveira \& Vasconcelos, 2010) and Thangiah, Osman and Sun (Thangiah, Osman, \& Sun, 1994). After the initial population is built up, these chromosomes are sorted by fitness, and then a pair of chromosomes is randomly chosen for mating using the ranking-based selection of Correa et al. (Correa et al., 2001), as shown in Eq. (35).

$$
\text { Select }(O S)=\left\{S_{p} \in O S, p=P-\left[\frac{-1+\sqrt{1+4 \cdot r n d\left(P^{2}+P\right)}}{2}\right]\right\}
$$

$O S$ is an ordered list of solutions sorted by fitness.

$p$ is the position in the OS to be selected as the chromosome $\mathrm{Sp}$. This formula is biased to favor the selection of chromosomes in early positions of the ordered list, like the best (smallest fitness)

rnd $(M)$ is a random distribution in the range 0 to $\mathrm{M}-1$

Next, with the crossover probability $\mathrm{p}_{\mathrm{c}}$, exchange parts of two selected chromosomes (Parents) and create two offspring (Child) as shown in Fig. 5

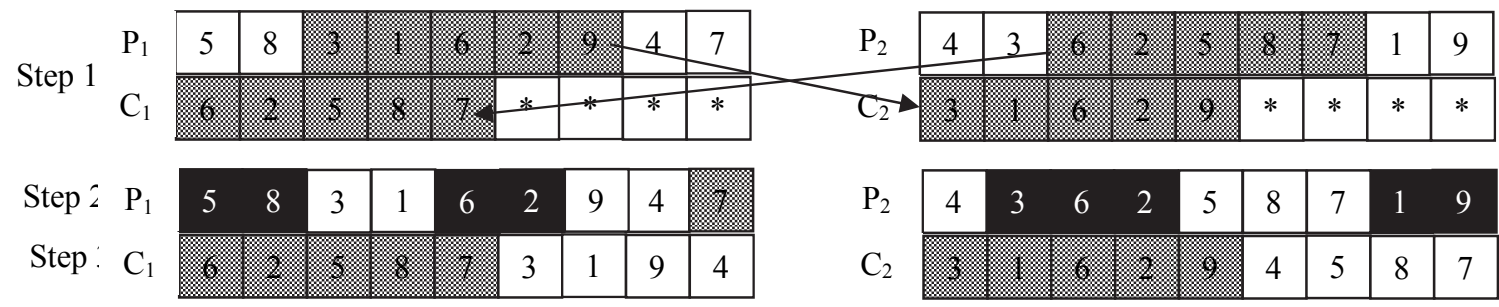

Fig. 5. Crossover procedure 
- Randomize indices cut 1 and cut 2 , whereas cut $1<$ cut 2

- Step 1: Copy customers/hospitals in parent-1 (P1) from indices cut1 to cut2 to child-2 (C2) starting at index 0. Also customers/hospitals in parent-2 (P2) from indices cut1 to cut2 to child-1 (C1) starting at index 0 .

- Step 2: mask customers/hospitals in P1 that already are contained in C1 and also mask customers in P2 that already are contained in $\mathrm{C} 2$.

- Step 3: fill customers that unmask in $\mathrm{C} 1$ to P1 and C2 to P2.

Like the crossover phase, with the mutation probability $\mathrm{p}_{\mathrm{m}}$, customers/hospitals in the two offspring chromosomes will be randomly swapped as shown in Fig. 6. This mutation procedure is repeated until the size of the new population is equal to P. After that, offspring and the old population (current population) will be combined and $\mathrm{P}$ chromosomes picked to be the new population using fitness. If a new chromosome is better than any chromosome in the current population, the new chromosome will be included and the worst one in the current population will be removed. Finally, the new chromosomes in the new population will be improved by three local searches, insertion-move, 2-opt and N-interexchange, as shown in Fig. 7, Fig. 8 and Fig. 9, respectively.

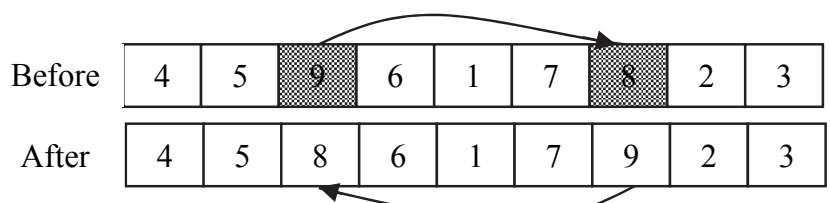

Fig. 6. Mutation procedure
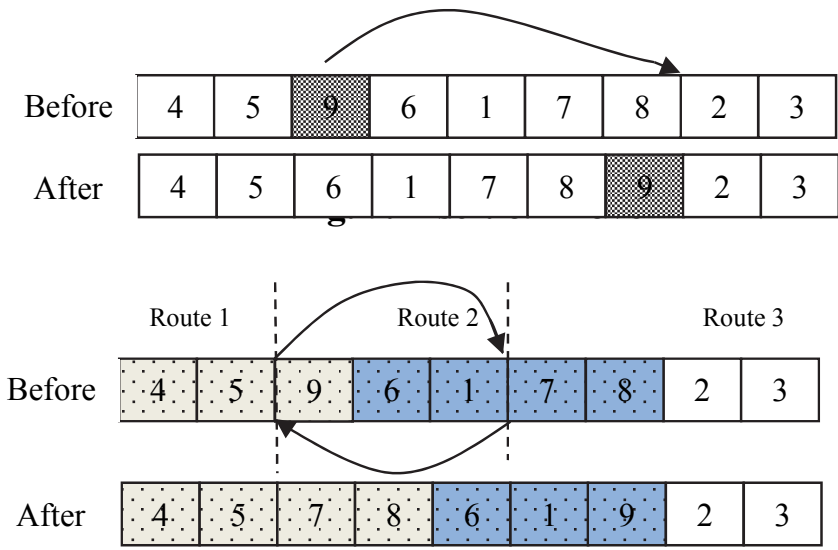

Fig. 8. 2-opt-move

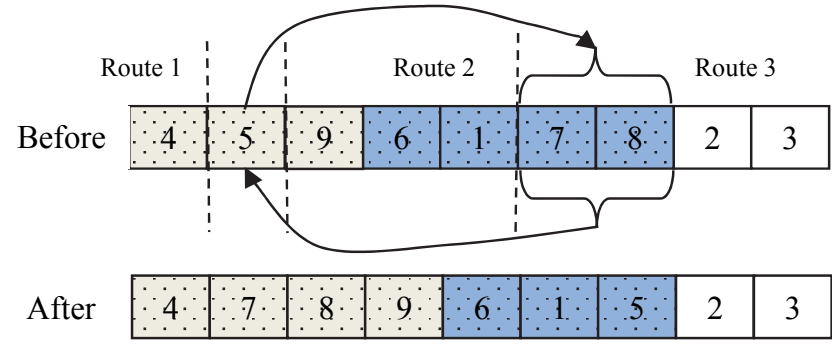

Fig. 9. N-interchange-move

The selection is still a ranking-based selection and chromosomes P times for each local search. This procedure is repeated until the stopping criteria are satisfied. Implementation and computational results of the HGA will be reported in next section. 


\section{Application}

In section 3, the HGP model was used to identify new suitable locations for infectious waste disposal in Upper-Northeastern Thailand. Six candidate municipalities, namely Maha Sarakham Town Municipality (MSTM), Nongbua Lamphu Town Municipality (NLTM), Kalasin Town Municipality (KTM), Sakon Nakhon City Municipality (SNCM), Nong Khai Town Municipality (NKTM) and Loei Town Municipality (LTM), were created from legislation, regulations and expertise by experts. New, suitable locations were selected from six candidate municipalities to serve the one hundred and seven community hospitals, namely H1, H2, ..., H107 (see details in Fig. 10), given the resource restrictions and preferences. The steps of the calculation are shown in sections 4.1 and 4.2.

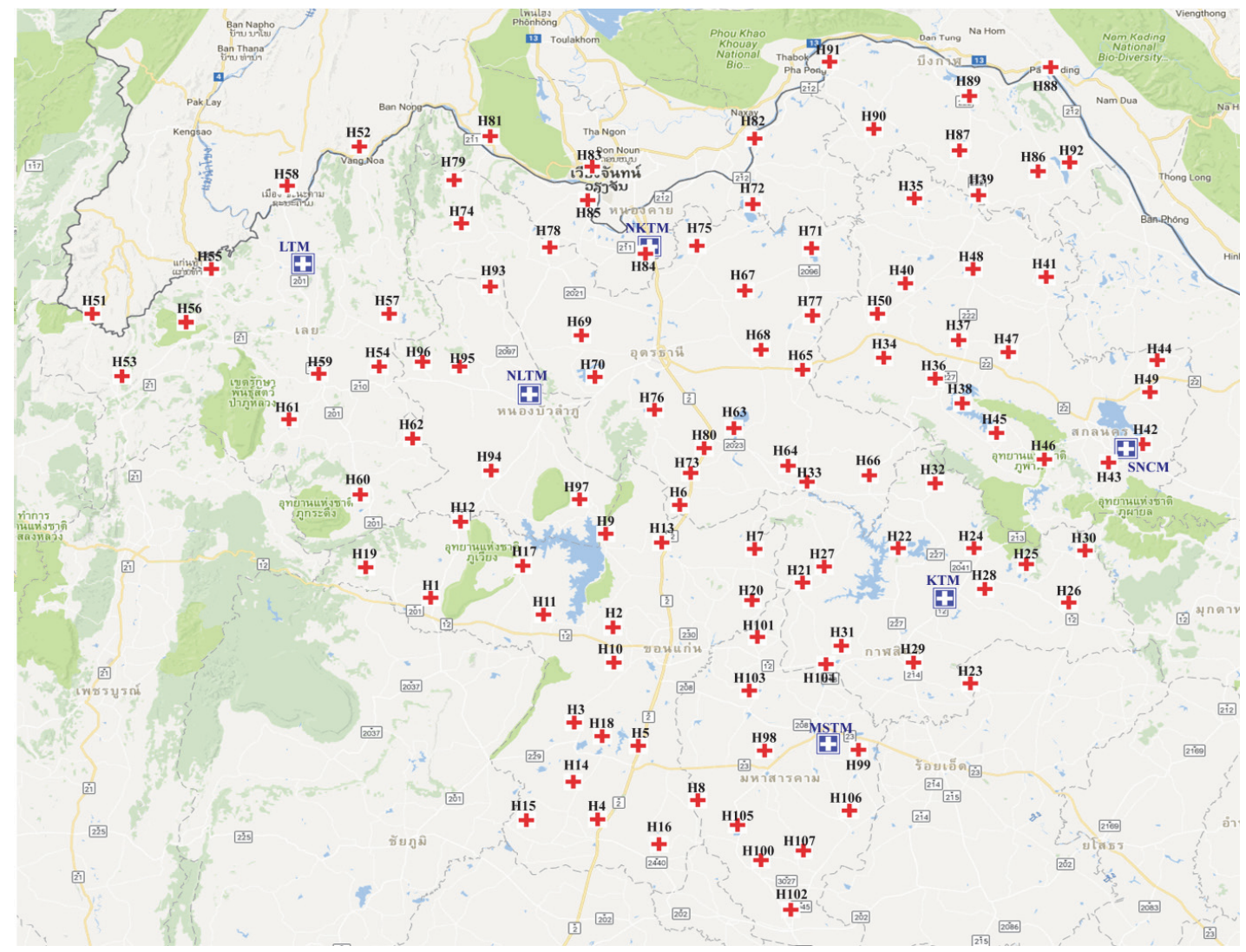

Fig. 10. The transportation network of candidate municipalities and community hospitals

\subsection{Evaluate the location weights of each candidate municipality using fuzzy AHP}

In this section, fuzzy AHP was used to determine location weights of each candidate municipality. Firstly, a three-level hierarchical structure for selecting infectious waste disposal centers was constructed by asking six experts and stakeholders (see Fig. 11). In the hierarchy, level 0 was the goal, the new suitable municipalities for infectious waste disposal, and level 1 was three main criteria, infrastructure $\left(\mathrm{C}_{1}\right)$, geological $\left(\mathrm{C}_{2}\right)$ and environmental \& social $\left(\mathrm{C}_{3}\right)$. Level 2 was ten sub-criteria, public utilities $\left(\mathrm{C}_{11}\right)$, traffic $\left(\mathrm{C}_{12}\right)$, area size $\left(\mathrm{C}_{21}\right)$, features of area $\left(\mathrm{C}_{22}\right)$, flooding in the past $\left(\mathrm{C}_{23}\right)$, density of population $\left(\mathrm{C}_{24}\right)$, municipal administrators $\left(\mathrm{C}_{31}\right)$, ability of municipalities $\left(\mathrm{C}_{32}\right)$, distance from communities $\left(\mathrm{C}_{33}\right)$ and distance from public water resources $\left(\mathrm{C}_{34}\right)$. Level 3 had six candidate municipalities, MSTM, NLTM, KTM, SNCM, NKTM and LTM. After obtaining a hierarchy for selecting a location for infectious waste disposal, fuzzy pair-wise comparison matrices were constructed for all levels (level 1 to level 3) from six decision makers who have worked in the field for more than fifteen years using the nine scale of fuzzy AHP (Table1). For example, in level 1, fuzzy pair-wise comparison matrices of three main criteria were 
constructed as shown in Table 3, and then the these matrices were aggregated into a fuzzy AHP combined matrix ( $\widetilde{G}$ ) by Eq. (6) as shown in Table 4 . The priority weights of level 1 were evaluated by three steps of estimating priority weights of each level and Eqs. (7-10), shown in Table 4 and Table 5. Finally, the global priority weights/location weights are shown in Table 6 ,

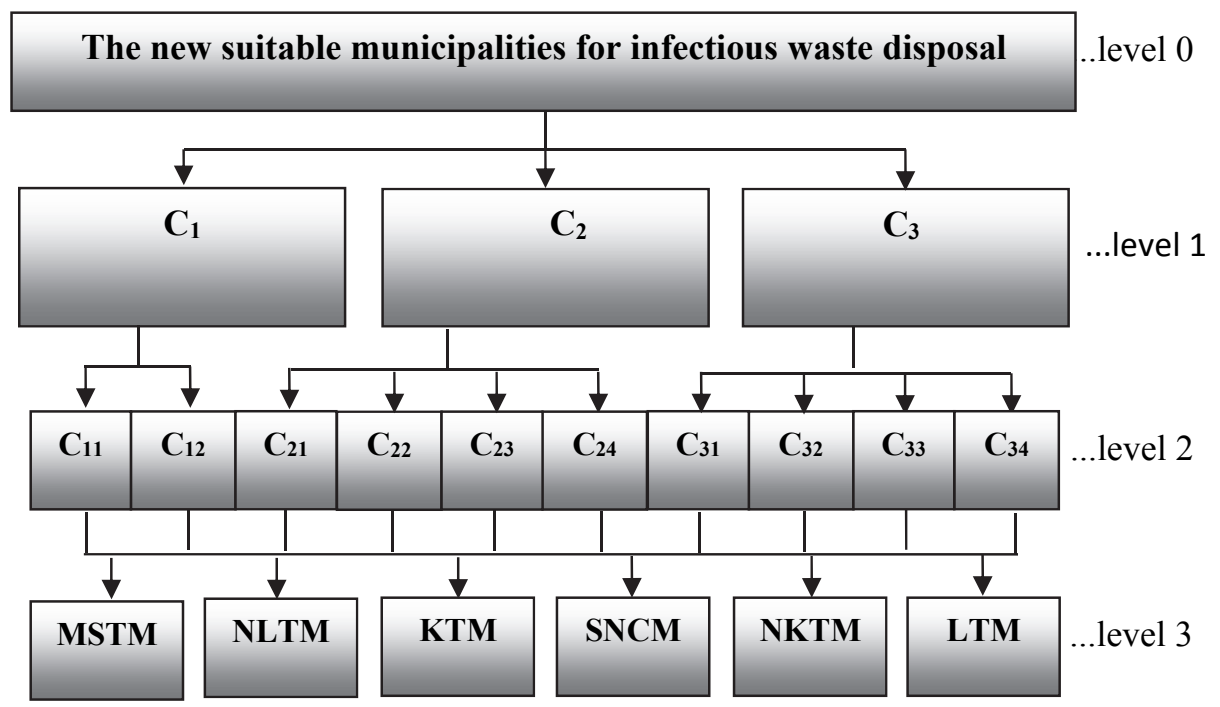

Fig. 11. A hierarchy for selecting location for infectious waste disposal

Table 3

The pair-wise comparison matrix of criteria with respect to goal by the six experts Goal

C1 $\quad(1.00,1.00,1.00),(1.00,1.00$, $1.00),(1.00,1.00,1.00),(1.00$, $1.00,1.00)(1.00,1.00,1.00)$ $(1.00,1.00,1.00)$

C2 $\quad(2.00,3.00,4.00),(4.00,5.00$, $6.00),(1.00,1.00,1.00),(0.25$, $0.33,0.50),(2.00,3.00,4.00)$, $(1.00,1.00,1.00)$

C3 $(8.00,9.00,9.00),(8.00,9.00$, $9.00),(6.00,7.00,8.00),(6.00$, $7.00,8.00),(8.00,9.00,9.00)$, $(4.00,5.00,6.00)$

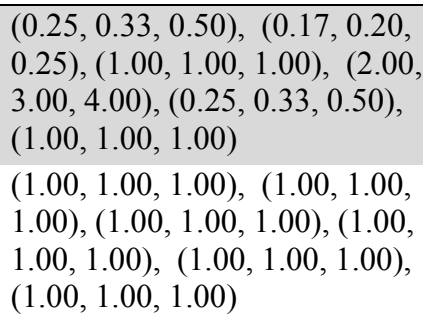

$(0.25,0.33,0.50),(0.17,0.20$, $0.25),(1.00,1.00,1.00),(2.00$, $3.00,4.00),(0.25,0.33,0.50)$, $(1.00,1.00,1.00)$

$(1.00,1.00,1.00),(1.00,1.00$, $1.00),(1.00,1.00,1.00),(1.00$, $1.00,1.00),(1.00,1.00,1.00)$, $(1.00,1.00,1.00)$

$(6.00,7.00,8.00),(6.00,7.00$, $8.00),(6.00,7.00,8.00),(6.00$, $7.00,8.00),(6.00,7.00,8.00)$, $(4.00,5.00,6.00)$
(0.11, 0.11, 0.13), (0.11, 0.11, $0.13),(0.13,0.14,0.17),(0.13$, $0.14,0.17),(0.11,0.11,0.13)$, $(0.17,0.20,0.25)$

$(0.13,0.14,0.17),(0.13,0.14$, $0.17),(0.13,0.14,0.17),(0.13$, $0.14,0.17),(0.13,0.14,0.17)$, $(0.17,0.20,0.25)$

$(1.00,1.00,1.00),(1.00,1.00$, $1.00),(1.00,1.00,1.00),(1.00$, $1.00,1.00),(1.00,1.00,1.00)$, $(1.00,1.00,1.00)$

Table 4

The integrated pair-wise comparison matrix of six experts.

\begin{tabular}{cccc}
\hline fuzzy AHP combined (goal) & $\mathrm{C} 1$ & $\mathrm{C} 2$ & $\mathrm{C} 3$ \\
\hline $\mathrm{C} 1$ & $(1,1,1)$ & $(0.52,0.64,0.79)$ & $(0.12,0.13,0.15)$ \\
$\mathrm{C} 2$ & $(1.26,1.57,1.91)$ & $(1,1,1)$ & $(0.13,0.15,0.18)$ \\
$\mathrm{C} 3$ & $(6.48,7.50,8.09)$ & $(5.61,6.62,7.63)$ & $(1,1,1)$ \\
\hline
\end{tabular}

Table 5 The normalization of integrated pair-wise comparison matrix

\begin{tabular}{|c|c|c|c|c|c|}
\hline Goal & $\mathrm{C}_{1}$ & $\mathrm{C}_{2}$ & $\mathrm{C}_{3}$ & $w c_{i}$ & $C R$ \\
\hline $\mathrm{C}_{1}$ & $(0.09,0.10,0.11)$ & $(0.06,0.08,0.11)$ & $(0.09,0.10,0.12)$ & 0.10 & \multirow{3}{*}{0.029} \\
\hline $\mathrm{C}_{2}$ & $(0.11,0.16,0.22)$ & $(0.11,0.12,0.14)$ & $(0.10,0.12,0.14)$ & 0.13 & \\
\hline $\mathrm{C}_{3}$ & $(0.59,0.74,0.93)$ & $(0.60,0.80,1.07)$ & $(0.75,0.78,0.80)$ & 0.77 & \\
\hline
\end{tabular}


Table 6

Location weights/global priority weights of candidate municipalities

\begin{tabular}{lc}
\hline \multicolumn{1}{c}{ Candidate municipalities } & Location weights $\left(w_{i}\right)$ \\
\hline Maha Sarakham Town Municipality (MSTM) & 0.179 \\
Nongbua Lamphu Town Municipality (NLTM) & 0.249 \\
Kalasin Town Municipality (KTM) & 0.110 \\
Sakon Nakhon City Municipality (SNCM) & 0.253 \\
Nong Khai Town Municipality (NKTM) & 0.094 \\
Loei Town Municipality (LTM) & 0.115 \\
\hline
\end{tabular}

\subsection{Compute the suitable locations for infectious waste disposal using the HGP model}

After obtaining the location weights of each candidate municipality, in order to solve the multi-objective facility location problem for infectious waste disposal, set $w_{o 1}=0.6, w_{o 2}=0.4$ according to experts' opinions. The demand and actual distance matrix of six candidate municipalities and one hundred and seven hospitals are shown in "the resource data for the HGP model" 1 as $d_{j}$, $d t_{i j}$. The value of $u$ is 4.3 baht $/ \mathrm{km}$. In Table 7, $f_{k}(k=1,2,3)$ are 9,244, 13,866 and 27,732 baht per day, and $o_{k}$ are 23,785, 31,074 and 51,497 baht per day respectively.

\section{Table 7}

Details of the cost

\begin{tabular}{|c|c|c|c|}
\hline \multirow[t]{2}{*}{ Details of the cost (baht/day) } & \multicolumn{3}{|c|}{$\begin{array}{c}\text { Size of incinerator } \\
(\mathrm{kg} / \text { day })\end{array}$} \\
\hline & 1,000 & 1,500 & 3,000 \\
\hline \multicolumn{4}{|l|}{ 1. Facility cost } \\
\hline 1.1 Incinerator and building facilities & 8,265 & 12,397 & 24,795 \\
\hline 1.2 Landfill & 46 & 68 & 137 \\
\hline 1.3 Storage & 658 & 986 & 1,973 \\
\hline 1.4 Infectious waste tank & 164 & 247 & 493 \\
\hline 1.5 Cleaning system & 11 & 16 & 33 \\
\hline 1.6 Emergency generator & 101 & 151 & 301 \\
\hline Total facility cost (baht/day) & 9,244 & 13,866 & 27,732 \\
\hline \multicolumn{4}{|l|}{ 2. Operating cost } \\
\hline 2.1 Labor cost & 9,929 & 10,849 & 12,296 \\
\hline 2.2 Maintenance costs ( $6 \%$ of incinerator) & 9,460 & 14,179 & 28,205 \\
\hline 2.3 Cost of measuring air pollution & 1,096 & 1,096 & 1,096 \\
\hline 2.4 Cost of IWD (3.3 Baht $/ \mathrm{kg})$ & 3,300 & 4,950 & 9,900 \\
\hline Total operating cost (baht/day) & 23,785 & 31,074 & 51,497 \\
\hline
\end{tabular}

\section{Table 8}

Optimal solution of HGP model

\begin{tabular}{|c|c|c|}
\hline Opened locations & $\begin{array}{c}\text { Size of locations } \\
(\mathrm{kg} / \text { day })\end{array}$ & Hospitals \\
\hline MSTM & 1,000 & 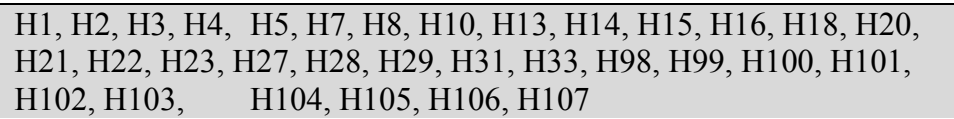 \\
\hline NLTM & 1,000 & 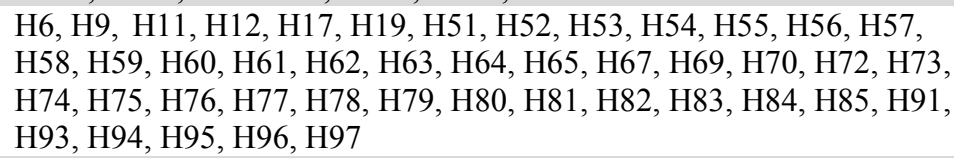 \\
\hline SNCM & 1,000 & $\begin{array}{l}\text { Н24, Н25, Н26, Н30, Н32, Н34, Н35, Н36, Н37, Н38, Н39, Н40, } \\
\text { H41, Н42, Н43, Н44, Н45, Н46, Н47, Н48, Н49, Н50, Н66, Н68, Н71, } \\
\text { H86, Н87, Н88, Н89, Н90, Н92 }\end{array}$ \\
\hline Total cost & 37913.37 baht/day & \\
\hline
\end{tabular}

${ }^{1}$ see details on https://sites.google.com/site/dataforijiec/ 
The values of $s k$ are 1,000 1,500 and 3,000 kg per day. The minimum total cost using Eqs.n $(11,13-19)$ was taken into Eq. (21) as the target of total cost $(T C)$ in the HGP model, $T C=142,133$ baht/day. Similarly, the location weights $\left(w_{i}\right)$ from Table 6 in section 4.1 were taken into Eq. (22), and the target of fuzzy AHP was equal to 1. After that, LINGO13 was applied using Eqs. (20-22) and Eqs. (13-19), and the optimal solution is shown in Table 8. Finally, the optimal solution was compared with the cost based model which used Eqs. (11, 13-19), as shown in Table 9.

Table 9

Comparison of Cost based model and HGP model

\begin{tabular}{cccc}
\hline Location & Location weights $\left(W_{i}\right)$ & Cost based model & HGP model \\
\hline MSTM & 0.179 & Not selected & Selected (incinerator size $=\mathbf{1 , 0 0 0 )}$ \\
NLTM & 0.249 & Selected (incinerator size $=\mathbf{1 , 5 0 0 )}$ & Selected (incinerator size $=\mathbf{1 , 0 0 0 )}$ \\
KTM & 0.110 & Selected (incinerator size $=\mathbf{1 , 5 0 0 )}$ & Not selected \\
SNCM & 0.253 & Not selected & Selected (incinerator size $=\mathbf{1 , 0 0 0 )}$ \\
NKTM & 0.094 & Not selected & Not selected \\
LTM & 0.115 & Not selected & Not selected \\
\hline & Total cost (Baht/day) & $\mathbf{1 4 2 , 1 3 3}$ & $\mathbf{1 4 2 , 6 2 7}$
\end{tabular}

As seen in Table 9, based on the cost based model, the results show that NLTM and KTM were the selected municipalities. The global priority weights/location weights of NLTM and KTM are 0.249 and 0.11 , respectively, and the total cost is 142,133 baht/day. After that, the HGP model was used to solve a multi-objective facility location problem in this case; the results show that the suitable candidate municipalities were MSTM, NLTM and SNCM. The location weights of these selected municipalities are $0.179,0.249$ and 0.253 , respectively, and the total cost is $142,627 \mathrm{baht} /$ day. Although the total cost of the HGP model was slightly higher than the selection of the cost based model, by about 494 baht, it can increase the satisfaction level (global priority weights) for new selected municipalities. Therefore, the proposed model can lead to choosing new suitable municipalities for infectious waste disposal by considering both tangible factors and intangible factors simultaneously.

Table 10

Sensitivity analysis for different levels of objective weights.

\begin{tabular}{|c|c|c|c|c|c|c|c|}
\hline & $\begin{array}{l}\text { Wo1 }=1.0, \\
\text { Wo } 2=0.0\end{array}$ & $\begin{array}{l}W_{01}=0.60 \\
W_{02}=0.40\end{array}$ & $\begin{array}{l}W_{01}=0.50 \\
W_{02}=0.50\end{array}$ & $\begin{array}{l}\text { Wo1 }=0.40 \\
W_{02}=0.60\end{array}$ & $\begin{array}{l}W_{01}=0.35 \\
W_{02}=0.65\end{array}$ & $\begin{array}{l}\text { Wo1 }=0.33 \\
W_{02}=0.67\end{array}$ & $\begin{array}{l}\text { Wo1 }=0.30 \\
W_{02}=0.70\end{array}$ \\
\hline MSTM & Not selected & Selected & Selected & Selected & Selected & Selected & Selected \\
\hline NLTM & Selected & Selected & Selected & Selected & Selected & Selected & Selected \\
\hline KTM & Selected & Not selected & Not selected & Not selected & Not selected & Selected & Selected \\
\hline SNCM & Not selected & Selected & Selected & Selected & Selected & Selected & Selected \\
\hline NKTM & Not selected & Not selected & Not selected & Not selected & Not selected & Not selected & Selected \\
\hline LTM & Not selected & Not selected & Not selected & Not selected & Selected & Selected & Selected \\
\hline $\begin{array}{c}\text { Total cost } \\
\text { (Baht/day) }\end{array}$ & 142,133 & 142,627 & 142,627 & 142,627 & 172,547 & 203,721 & 233,136 \\
\hline $\begin{array}{c}\text { Total location } \\
\text { weights }\end{array}$ & 0.359 & 0.681 & 0.681 & 0.681 & 0.796 & 0.906 & 1.00 \\
\hline
\end{tabular}

The sensitivity analysis of the HGP model was also performed for different levels of objective weights in order to evaluate the influence of objective weights on the multi-objective facility location problem in this case. The results are summarized in Table 10, and Fig. 12 and Fig. 13. It is seen that by increasing $w_{o 1}$ and decreasing $w_{o 2}$ at the same time, the total cost goal has a decreasing trend (lowest total cost). On the other hand, it is seen that by decreasing $w_{01}$ and increasing $w_{o 2}$ at the same time, the number of locations and total cost have an increasing trend. Finally, these solutions from sensitivity analysis in Table 10 were offered to the six decision makers. As a result, the decision makers confirm that these municipalities (MSTM, NLTM and SNCM) are suitable as new infectious waste disposal centers, and 
they believe that our proposed work can provide essential support for decision makers in the assessment of infectious waste disposal management problems in this case study and other areas of Thailand.

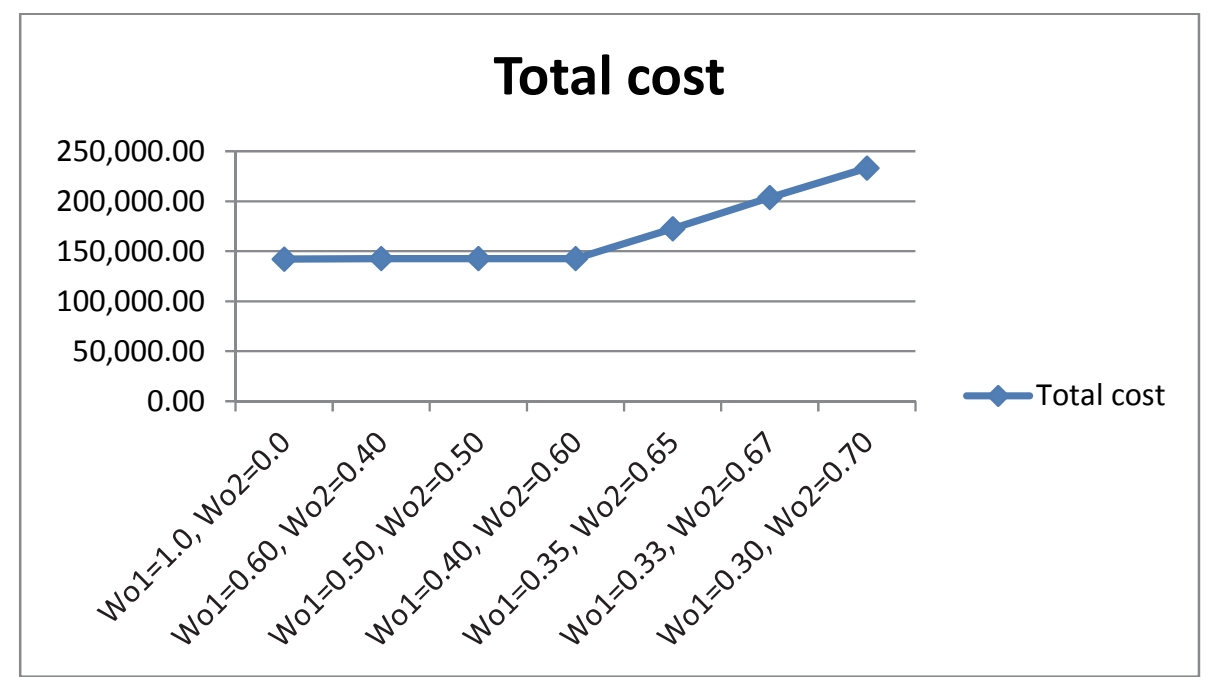

Fig. 12. Sensitivity analysis of total cost for different levels of $w_{o l}, w_{o 2}$

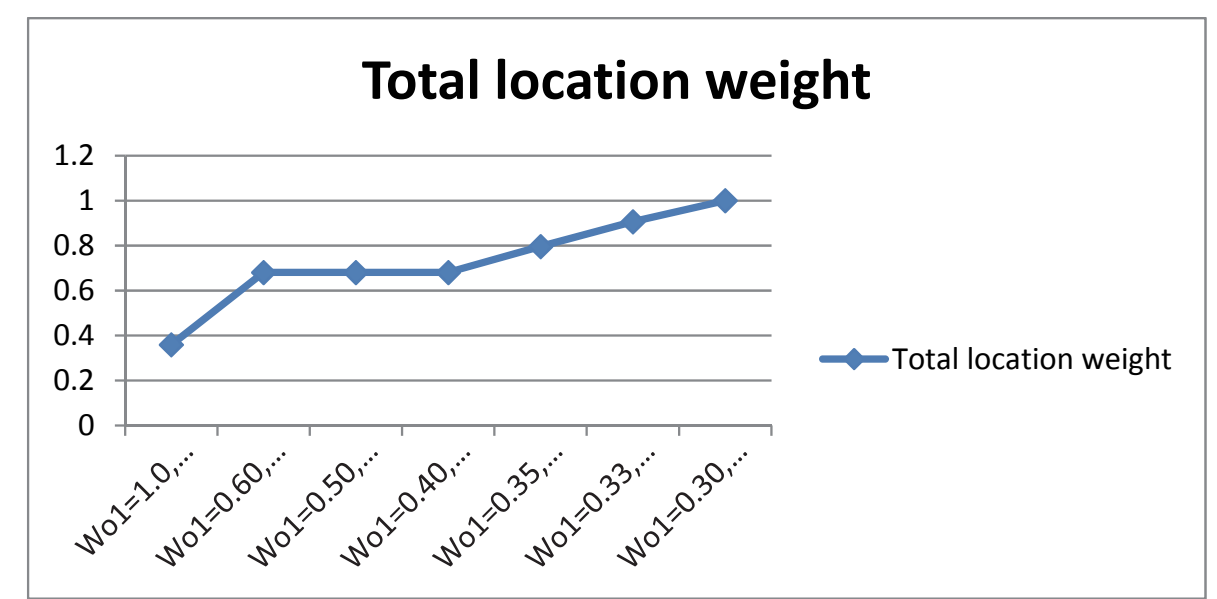

Fig. 13. Sensitivity analysis of total location weight for different levels of $w_{o 1}, w_{o 2}$

\subsection{Compute the transport routes for infectious waste disposal centers using HGP model}

Based on the actual situation of this case, each hospital was determined to be served by each disposal center once a week, and in fact, the size of the vehicles was determined after creating the best transport routes/minimum total distance of the artificial vehicles in order to minimize transportation cost. Therefore, the size of artificial vehicles in this problem was not capacitated. Demand of each hospital $\left(d_{j}\right)$ was changed as the demand for seven days. Actual distance matrices $\left(d t_{i j}\right)$ and $d_{j}$ of each cluster are shown in "distance matrix of each cluster"2 respectively.

The experiment was performed on a computer with the following characteristics: an Intel ${ }^{\circledR}$ Core ${ }^{\mathrm{TM}} \mathrm{i} 5$ $4210 \mathrm{U}$ processor Dual-core with $1.70 \mathrm{GHz}$ with $8 \mathrm{~GB}$ of RAM, and Windows 8.1 operating system. The capacity of all vehicles $\left(q_{k}\right)$ is not capacitated, equal to 300,000 kg. Each vehicle travels from node $i$ to $j$ at a constant speed of 60 kilometers per hour so the maximum allowable time (TT) is equal to 480 minutes according to the experts' opinions. The input parameters for the experimentation in HGA were made with

${ }^{2}$ see details on https://sites.google.com/site/dataforijiec/ 
an initial population of 100 individuals and 10 generations, and HGA was tested to solve the actual problems using visual studio $2015(\mathrm{C}++)$. The weights for the three criteria of PFIH were set to $\alpha=0.7$, $\beta=0.1$ and $\gamma=0.2$, and the probability for genetic operator in HGA were set to crossover probability $\left(p_{c}\right)$ $=0.8$ and the mutation probability $\left(p_{m}\right)=0.3$. The obtained results are compared with computational results using LINGO13 based on the VRP model in section 4.3, as shown in Table 11.

From Problem $1.1(\mathrm{~N}=5)$, Problem $1.2(\mathrm{~N}=10)$, Problem $1.3(\mathrm{~N}=15)$ and Problem 1.4 $(\mathrm{N}=33)$, MSTM has been selected as a disposal center which needs to service 4 hospitals (H1, H2, H3, H4), 9 hospitals (H1, H2, H3, H4, H5, H7, H8, H10, H13), 14 hospitals (H1, H2, H3, H4, H5, H7, H8, H10, H13, H14, $\mathrm{H} 15, \mathrm{H} 16, \mathrm{H} 18, \mathrm{H} 20)$ and 32 hospitals respectively.

From Problem 2.1 ( $=5)$, Problem 2.2 $(\mathrm{N}=10)$, Problem $2.3(\mathrm{~N}=15)$ and Problem $2.4(\mathrm{~N}=45)$, NLTM has been selected as a disposal center which needs to service 4 hospitals (H6, H9, H11, H12), 9 hospitals (H6, H9, H11, H12, H17, H19, H51, H52, H53), 14 hospitals (H6, H9, H11, H12, H17, H19, H51, H52, H53, H54, H55, H56, H57, H58) and 44 hospitals respectively.

From Problem $3.1(\mathrm{~N}=5)$, Problem $3.2(\mathrm{~N}=10)$, Problem $3.3(\mathrm{~N}=15)$ and Problem $3.4(\mathrm{~N}=32)$, SNCM has been selected as a disposal center which needs to service 4 hospitals (H24, H25, H26, H30), 9 hospitals (H24, H25, H26, H30, H32, H34, H35, H36, H37), 14 hospitals (H24, H25, H26, H30, H32, H34, H35, H36, H37, H38, H39, H40, H41, H42) and 31 hospitals respectively.

Table 11

Comparison of solutions using LINGO13 and HGA

\begin{tabular}{|c|c|c|c|c|c|c|c|}
\hline Data set & $\begin{array}{c}\text { Municipality's } \\
\text { name/Number of } \\
\text { hospitals }\end{array}$ & $\begin{array}{l}\text { Number of } \\
\text { artificial } \\
\text { vehicles } \\
(\mathrm{NV})\end{array}$ & $\begin{array}{l}\text { LINGO13 } \\
\text { Total distance } \\
\text { (TD) }\end{array}$ & $\begin{array}{l}\text { Computational } \\
\text { times } \\
(\mathrm{hh}, \mathrm{mm}, \mathrm{ss})\end{array}$ & $\begin{array}{l}\text { Number of } \\
\text { artificial } \\
\text { vehicles } \\
(\mathrm{NV})\end{array}$ & $\begin{array}{c}\text { HGA } \\
\text { Total distance } \\
\text { (TD) }\end{array}$ & Deviation \\
\hline $\begin{array}{c}\text { Problem } \\
1.1\end{array}$ & MSTM/4 hos. & 1 & 423.0 & 00:00:00 & 1 & 423.0 & $0 \%$ \\
\hline $\begin{array}{l}\text { Problem } \\
1.2\end{array}$ & MSTM/9 hos. & 2 & 703.9 & 00:00:58 & 2 & 703.9 & $0 \%$ \\
\hline $\begin{array}{c}\text { Problem } \\
1.3\end{array}$ & MSTM/14 hos. & 2 & 764.7 & 39:05:00 & 2 & 764.7 & $0 \%$ \\
\hline $\begin{array}{c}\text { Problem } \\
1.4\end{array}$ & $\begin{array}{l}\text { MSTM/32 hos. } \\
\text { (Actual problem) }\end{array}$ & 3 & $1,245^{*}$ & 48:00:00 & 3 & 1,245 & $0 \%$ \\
\hline $\begin{array}{l}\text { Problem } \\
2.1\end{array}$ & NLTM/4 hos. & 1 & 338.7 & 00:00:00 & 1 & 338.7 & $0 \%$ \\
\hline $\begin{array}{l}\text { Problem } \\
2.2\end{array}$ & NLTM/9 hos. & 3 & 1181.5 & 00:00:26 & 3 & $1,181.5$ & $0 \%$ \\
\hline $\begin{array}{l}\text { Problem } \\
2.3\end{array}$ & NLTM/14 hos. & 3 & 1168.1 & 05:08:37 & 3 & $1,168.1$ & $0 \%$ \\
\hline $\begin{array}{l}\text { Problem } \\
2.4\end{array}$ & $\begin{array}{l}\text { NLTM/44 hos. } \\
\text { (Actual problem) }\end{array}$ & 5 & $2,159.5^{*}$ & 48:00:00 & 5 & $2,159.5$ & $0 \%$ \\
\hline $\begin{array}{c}\text { Problem } \\
3.1\end{array}$ & SNCM/4 hos. & 1 & 204.0 & 00:00:00 & 1 & 204.0 & $0 \%$ \\
\hline $\begin{array}{l}\text { Problem } \\
3.2\end{array}$ & SNCM /9 hos. & 1 & 471.1 & 00:00:00 & 1 & 471.1 & $0 \%$ \\
\hline $\begin{array}{c}\text { Problem } \\
3.3\end{array}$ & SNCM /14 hos. & 2 & 693.7 & 07:59:42 & 2 & 693.7 & $0 \%$ \\
\hline $\begin{array}{c}\text { Problem } \\
3.4\end{array}$ & $\begin{array}{c}\text { SNCM /31 hos. } \\
\text { (Actual problem ) }\end{array}$ & 3 & $1,322.1 *$ & 48:00:00 & 3 & 1322.1 & $0 \%$ \\
\hline
\end{tabular}

* Computational results (feasible solutions) of actual problems at computational time of 48 hrs.

As seen in Table 11, the computational results show that the optimal solutions for small size problem $(\mathrm{N}=5, \mathrm{~N}=10$ and $\mathrm{N}=15)$ were achieved using LINGO13 and HGA. In addition, the computational results using HGA for all actual cases achieved best known solutions at computational times of $48 \mathrm{hrs}$ using LINGO13. Details of computational results for the actual problems are shown in Table 12, and then the actual costs of a case study are shown in Table 13. 
Table 12

Details of computational results for the actual problems using HGA

\begin{tabular}{|c|c|c|c|}
\hline Disposal centers & Transport routes & $\begin{array}{l}\text { Distance } \\
(\mathrm{km})\end{array}$ & $\begin{array}{c}\text { Amount } \\
\text { of infectious waste } \\
(\mathrm{kg}) \\
\end{array}$ \\
\hline \multirow{4}{*}{ MSTM } & $\begin{array}{l}\text { Route 1: MSTM, H99, H106, H107, H102, } \\
\text { H100, H105, H8, H16, H4, H15, H14, H18, H3, } \\
\text { H5, H98, MSTM }\end{array}$ & 401.0 & $2,941.54$ \\
\hline & $\begin{array}{l}\text { Route 2: MSTM, H23, H29, H28, H22, H27, } \\
\text { H33, H21, H31, H104, MSTM }\end{array}$ & 408.9 & $1,258.60$ \\
\hline & $\begin{array}{l}\text { Route 3: MSTM, H10, H2, H1, H13, H7, H20, } \\
\text { H101, H103, MSTM }\end{array}$ & 436.7 & $2,758.07$ \\
\hline & Total & $1,246.6$ & $6,958.21$ \\
\hline \multirow{6}{*}{ NLTM } & $\begin{array}{l}\text { Route 1: NLTM, H96, H57, H55, H51, H53, } \\
\text { H56, H61, H59, H54, NLTM }\end{array}$ & 451.0 & $1,264.13$ \\
\hline & $\begin{array}{l}\text { Route 2: NLTM, H78, H83, H85, H82, H91, } \\
\text { H72, H75, H84, NLTM }\end{array}$ & 448.9 & $1,064.56$ \\
\hline & $\begin{array}{l}\text { Route 3: NLTM, H95, H58, H52, H81, H79, } \\
\text { H74, H93, H69, H70, NLTM }\end{array}$ & 434.6 & $1,452.99$ \\
\hline & $\begin{array}{l}\text { Route 4: NLTM, H67, H77, H65, H64, H63, } \\
\text { H80, H76, H73, H6, H9, H97, NLTM }\end{array}$ & 438.7 & $1,869.07$ \\
\hline & $\begin{array}{l}\text { Route 5: NLTM, H12, H17, H11, H19, H60, } \\
\text { H62, H94, NLTM }\end{array}$ & 370.6 & $1,296.05$ \\
\hline & Total & $2,143.8$ & $6,946.8$ \\
\hline \multirow{4}{*}{ SNCM } & $\begin{array}{l}\text { Route 1: SNCM, H41, H92, H86, H88, H44, } \\
\text { H49, H42, SNCM }\end{array}$ & 413 & $1,427.37$ \\
\hline & $\begin{array}{l}\text { Route 2: SNCM, H30, H26, H25, H24, H32, } \\
\text { H66, H68, H34, H36, H38, H45, H46, H43, } \\
\text { SNCM }\end{array}$ & 433.5 & $2,716.4$ \\
\hline & $\begin{array}{l}\text { Route 3: SNCM, H47, H37, H40, H50, H71, } \\
\text { H35, H90, H87, H89, H39, H48, SNCM }\end{array}$ & 462.0 & $2,837.8$ \\
\hline & Total & $\mathbf{1 , 3 0 8 . 5}$ & $6,981.57$ \\
\hline
\end{tabular}

Table 13

The actual costs of a case study

\begin{tabular}{cccc}
\hline $\begin{array}{c}\text { Details of the cost } \\
\text { (baht/day) }\end{array}$ & MSTM/1,000 & $\begin{array}{c}\text { Selected municipality/incinerator size } \\
\text { NLTM } / 1,000\end{array}$ & SNCM $/ 1,000$ \\
\hline Facility cost & 9,244 & 9,244 & 9,244 \\
Operating cost & $23,785+2,195.89=25,980.89$ & $23,785+1,921.91=25,706.92$ & $23,785+2,195.89=25,980.89$ \\
Transportation cost & $1,246.6 \mathrm{~km} \times 4.3 \mathrm{baht} / \mathrm{km}=$ & $2,143.8 \mathrm{~km} \times 4.3 \mathrm{baht} / \mathrm{km}=$ & $1,308.5 \mathrm{~km} \times 4.3 \mathrm{baht} / \mathrm{km}=$ \\
& $5,360.38 \mathrm{baht} / \mathrm{week}=765.77$ & $9,218.34 \mathrm{baht} / \mathrm{week}=1,316.91$ & $5,626.55 \mathrm{baht} / \mathrm{week}=803.79$ \\
\hline Total & $35,990.66$ & $36,267.83$ & $36,028.68$ \\
Actual total cost & & $35,990.66+36,267.83+36,028.68=108,287.17$ & \\
\hline
\end{tabular}

As seen in Table 12, in practice based on actual situation and according to decision makers' opinions, infectious waste which is generated at hospitals should be serviced from any selected municipality once a week using a minimum number of vehicles. Any vehicle used to transport infectious waste should be of a suitable size, commensurate with the design of the routes and mobility of the service. Hence, there are three sizes of special vehicles, capacity of $1,000 \mathrm{~kg}$, capacity of 2,000 $\mathrm{kg}$ and capacity of 3,000 kg, which are often used and recommended for infectious waste collection in Thailand. The prices of these special vehicles for waste collection are about 2 million baht, 3 million baht and 4 million baht respectively. Therefore, in order to minimize transportation costs and number of vehicles according to decision makers' opinions, a capacity of 3,000 was selected as a suitable size for MSTM, and it has been planned to pick up the infectious waste on Monday (Route 1), Tuesday (Route 2) and Wednesday (Route 3 ). A capacity of 2,000 was selected as a suitable size for NLTM, and it has been planned to pick up the infectious waste on Monday (Route 1), Tuesday (Route 2) and Wednesday (Route 3). Finally, a capacity of 3,000 was selected as a suitable size for SNCM, and it has been planned to pick up the infectious waste 
on Monday (Route 1), Tuesday (Route 2) and Wednesday (Route 3). The actual total cost in the case study is equal to $108,287.17$ baht/day, $35990.66+36,267.83+36,028.68=108,287.17 \mathrm{baht} /$ day, as shown in Table 13.

As seen in Table 12 and Table 13, the proposed HGA can lead to choosing transport routes which provide minimum transportation costs effectively, and it also provides the minimum number of vehicles under this actual case study, according to decision makers' opinions.

\section{Conclusion}

As presented in this paper, the location routing problem for infectious waste disposal is a complex, multistage process. As indicated by the authors it can be split into two phases, including: 1) the multi-objective facility location problem, the analysis of the regions being the potential locations for infectious waste disposal; 2) the vehicle routing problem, the analysis of transport routes in the selected location, which is to minimize transportation cost/total distance. In the first stage of this paper, the authors have presented a model in order to solve multi-objective facility location problems with both quantitative and qualitative objectives. This model was tested with a case study, for 107 hospitals and 6 candidate municipalities, in Upper-Northeastern Thailand. Firstly, the fuzzy AHP was applied to determine the global priority weights of each location/ location weights. Secondly, the HGP model (multi-objective facility location problem model) was formulated to solve this complex problem in a case study, the global priority weights of fuzzy AHP were taken into the proposed model. Finally, the optimal solution was computed by LINGO13 to select the new suitable locations for infectious waste disposal. The results show that MSTM, NLTM and SNCM were the suitable locations. Even though for these selected locations, the total cost is slightly higher than the selection by the cost based model, by about 494 baht/day, the suitable global priority weight was achieved using the HGP model. In the second stage of this paper, the authors have presented an HGA model in order to solve VRP under the actual situation. Firstly, LINGO13 was applied to solve the VRP model in order to compare with HGA which was formulated to solve large size problems in a case study. Finally, the solutions were planned for infectious waste pickup by decision makers. The results show that selected municipalities were assigned for infectious waste pickup efficiently, using the minimum number of vehicles and minimum transportation cost in the decision makers' opinions.

The major advantages of the proposed methodologies are that the hybrid goal programming model (HGP) can guide selection of new suitable locations by considering quantitative and qualitative factors simultaneously, and the hybrid genetic algorithm can determine the transport routes which require the minimum number of vehicles and minimum transportation cost under the actual situation in this case efficiently. Therefore, it is believed that these approaches should be more valuable and applicable than stand-alone optimization techniques.

\section{Acknowledgements}

The authors are very grateful to the Department of Industrial Engineering, Khon Kaen University and Kalasin University for supporting this research. The authors would like to express sincere gratitude to those municipalities and hospitals in Upper-Northeastern Thailand who provided valuable time and information for this research, but whose names unfortunately cannot be revealed because of the confidentiality agreement. Finally, the authors would like to thank the reviewers for their valuable comments and recommendations which enabled the improvement of the quality of this paper.

\section{References}

Ahmadizar, F., Zeynivand, M., \& Arkat, J. (2015). Two-level vehicle routing with cross-docking in a three-echelon supply chain: A genetic algorithm approach. Applied Mathematical Modelling, 39(22), 7065-7081. 
Alumur, S., \& Kara, B. Y. (2007). A new model for the hazardous waste location-routing problem. Computers \& Operations Research, 34(5), 1406-1423.

Badri, M. A. (1999). Combining the analytic hierarchy process and goal programming for global facility locationallocation problem. International Journal of Production Economics, 62(3), 237-248.

Baker, B. M., \& Ayechew, M. A. (2003). A genetic algorithm for the vehicle routing problem. Computers \& Operations Research, 30(5), 787-800.

Birim, Ş. (2016). Vehicle Routing Problem with Cross Docking: A Simulated Annealing Approach. ProcediaSocial and Behavioral Sciences, 235, 149-158.

Brandão, J. (2009). A deterministic tabu search algorithm for the fleet size and mix vehicle routing problem. European Journal of Operational Research, 195(3), 716-728.

Brandão, J. (2011). A tabu search algorithm for the heterogeneous fixed fleet vehicle routing problem. Computers \& Operations Research, 38(1), 140-151.

Brandão de Oliveira, H. C., \& Vasconcelos, G. C. (2010). A hybrid search method for the vehicle routing problem with time windows. Annals of Operations Research, 180(1), 125-144.

Choudhary, D., \& Shankar, R. (2012). An STEEP-fuzzy AHP-TOPSIS framework for evaluation and selection of thermal power plant location: A case study from India. Energy, 42(1), 510-521.

Clarke, G., \& Wright, J. W. (1964). Scheduling of vehicles from a central depot to a number of delivery points. Operations Research, 12(4), 568-581.

Correa, E. S., Steiner, M. T. A., Freitas, A. A., \& Carnieri, C. (2001, July). A genetic algorithm for the p-median problem. In Proceedings of the 3rd Annual Conference on Genetic and Evolutionary Computation (pp. 12681275). Morgan Kaufmann Publishers Inc.

Dantrakul, S., Likasiri, C., \& Pongvuthithum, R. (2014). Applied p-median and p-center algorithms for facility location problems. Expert Systems with Applications, 41(8), 3596-3604.

Dantzig, G. B., \& Ramser, J. H. (1959). The truck dispatching problem. Management Science, 6(1), 80-91.

Dong, Q., \& Cooper, O. (2016). A peer-to-peer dynamic adaptive consensus reaching model for the group AHP decision making. European Journal of Operational Research, 250(2), 521-530.

Etemadnia, H., Goetz, S. J., Canning, P., \& Tavallali, M. S. (2015). Optimal wholesale facilities location within the fruit and vegetables supply chain with bimodal transportation options: An LP-MIP heuristic approach. European Journal of Operational Research, 244(2), 648-661.

Farahani, R. Z., SteadieSeifi, M., \& Asgari, N. (2010). Multiple criteria facility location problems: A survey. Applied Mathematical Modelling, 34(7), 1689-1709.

Golmohammadi, A., Bani-Asadi, H., Zanjani, H., \& Tikani, H. (2016). A genetic algorithm for preemptive scheduling of a single machine. International Journal of Industrial Engineering Computations, 7(4), 607-614.

Guastaroba, G., \& Speranza, M. G. (2014). A heuristic for BILP problems: the single source capacitated facility location problem. European Journal of Operational Research, 238(2), 438-450.

Guo, P., Cheng, W., \& Wang, Y. (2017). Hybrid evolutionary algorithm with extreme machine learning fitness function evaluation for two-stage capacitated facility location problems. Expert Systems with Applications, 71, 57-68.

Hanine, M., Boutkhoum, O., Tikniouine, A., \& Agouti, T. (2016). Comparison of fuzzy AHP and fuzzy TODIM methods for landfill location selection. SpringerPlus, 5(1), 501.

Hansakul, A., Pitaksanurat, S., Srisatit, T., \& Surit, P. (2010). Infectious waste management in the government hospitals by private transport sector: Case study of hospitals in the north east of Thailand. Journal of Environmental Research And Development, 4(4), 1070-1077.

Ho, W. (2007, October). Combining analytic hierarchy process and goal programming for logistics distribution network design. In Systems, Man and Cybernetics, 2007. ISIC. IEEE International Conference on (pp. 714719). IEEE.

He, T., Ho, W., Lee Ka Man, C., \& Xu, X. (2012). A fuzzy AHP based integer linear programming model for the multi-criteria transshipment problem. The International Journal of Logistics Management, 23(1), 159-179.

Ho, W., Ho, G. T., Ji, P., \& Lau, H. C. (2008). A hybrid genetic algorithm for the multi-depot vehicle routing problem. Engineering Applications of Artificial Intelligence, 21(4), 548-557.

Ho, W., Lee, C. K. M., \& Ho, G. T. S. (2008). Optimization of the facility location-allocation problem in a customer-driven supply chain. Operations Management Research, 1(1), 69-79.

Holland, J. H. (1992). Adaptation in natural and artificial systems: an introductory analysis with applications to biology, control, and artificial intelligence. MIT press.

Kahraman, C., Ruan, D., \& Doğan, I. (2003). Fuzzy group decision-making for facility location selection. Information Sciences, 157, 135-153. 
Kalayci, C. B., \& Kaya, C. (2016). An ant colony system empowered variable neighborhood search algorithm for the vehicle routing problem with simultaneous pickup and delivery. Expert Systems with Applications, 66, 163175.

Kalcsics, J., Nickel, S., Pozo, M. A., Puerto, J., \& Rodríguez-Chía, A. M. (2014). The multicriteria p-facility median location problem on networks. European Journal of Operational Research, 235(3), 484-493.

Kannan, D., Khodaverdi, R., Olfat, L., Jafarian, A., \& Diabat, A. (2013). Integrated fuzzy multi criteria decision making method and multi-objective programming approach for supplier selection and order allocation in a green supply chain. Journal of Cleaner Production, 47, 355-367.

Karakatič, S., \& Podgorelec, V. (2015). A survey of genetic algorithms for solving multi depot vehicle routing problem. Applied Soft Computing, 27, 519-532.

Lai, D. S., Demirag, O. C., \& Leung, J. M. (2016). A tabu search heuristic for the heterogeneous vehicle routing problem on a multigraph. Transportation Research Part E: Logistics and Transportation Review, 86, 32-52.

Lenstra, J. K., \& Kan, A. H. G. (1981). Complexity of vehicle routing and scheduling problems. Networks, 11(2), 221-227.

Miyazaki, M., \& Une, H. (2005). Infectious waste management in Japan: A revised regulation and a management process in medical institutions. Waste management, 25(6), 616-621.

Nagy, G., \& Salhi, S. (2007). Location-routing: Issues, models and methods. European Journal of Operational Research, 177(2), 649-672.

Nazari, A., Salarirad, M. M., \& Bazzazi, A. A. (2012). Landfill site selection by decision-making tools based on fuzzy multi-attribute decision-making method. Environmental Earth Sciences, 65(6), 1631-1642.

Osman, I. H., \& Christofides, N. (1994). Capacitated clustering problems by hybrid simulated annealing and tabu search. International Transactions in Operational Research, 1(3), 317-336.

Ozgen, D., \& Gulsun, B. (2014). Combining possibilistic linear programming and fuzzy AHP for solving the multiobjective capacitated multi-facility location problem. Information Sciences, 268, 185-201.

Potvin, J. Y., \& Rousseau, J. M. (1995). An exchange heuristic for routeing problems with time windows. Journal of the Operational Research Society, 46(12), 1433-1446.

Rahmani, A., \& MirHassani, S. A. (2014). A hybrid firefly-genetic algorithm for the capacitated facility location problem. Information Sciences, 283, 70-78.

Razali, N. M. (2015). An efficient genetic algorithm for large scale vehicle routing problem subject to precedence constraints. Procedia - Social and Behavioral Sciences, 195, 1922-1931. doi: http://dx.doi.org/10.1016/j.sbspro.2015.06.203

de FSM Russo, R., \& Camanho, R. (2015). Criteria in AHP: a systematic review of literature. Procedia Computer Science, 55, 1123-1132.

Singh, R. P., \& Nachtnebel, H. P. (2016). Analytical hierarchy process (AHP) application for reinforcement of hydropower strategy in Nepal. Renewable and Sustainable Energy Reviews, 55, 43-58.

Solomon, M. M. (1987). Algorithms for the vehicle routing and scheduling problems with time window constraints. Operations research, 35(2), 254-265.

Steiner, M. T. A., Datta, D., Neto, P. J. S., Scarpin, C. T., \& Figueira, J. R. (2015). Multi-objective optimization in partitioning the healthcare system of Parana State in Brazil. Omega, 52, 53-64.

Tang, J., Ma, Y., Guan, J., \& Yan, C. (2013). A max-min ant system for the split delivery weighted vehicle routing problem. Expert Systems with Applications, 40(18), 7468-7477.

Tavakkoli-Moghaddam, R., Safaei, N., Kah, M. M. O., \& Rabbani, M. (2007). A new capacitated vehicle routing problem with split service for minimizing fleet cost by simulated annealing. Journal of the Franklin Institute, 344(5), 406-425.

Thangiah, S. R., Osman, I. H., \& Sun, T. (1994). Hybrid genetic algorithm, simulated annealing and tabu search methods for vehicle routing problems with time windows. Computer Science Department, Slippery Rock University, Technical Report SRU CpSc-TR-94-27, 69.

Zadeh, L. A. (1965). Fuzzy sets. Information and Control, 8(3), 338-353.

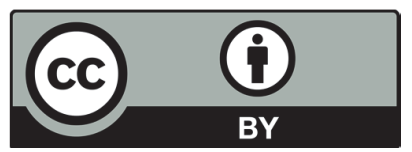

(C) 2017 by the authors; licensee Growing Science, Canada. This is an open access article distributed under the terms and conditions of the Creative Commons Attribution (CCBY) license (http://creativecommons.org/licenses/by/4.0/). 